\title{
Endless Leverage Certificates
}

\author{
Jos van Bommel ${ }^{\mathrm{a},}{ }^{*}$, Silvia Rossetto ${ }^{\mathrm{b}}$ \\ ${ }^{\text {a }}$ Saïd Business School, University of Oxford, Park End Street, Oxford, OX1 1HP, U.K. \\ ${ }^{\mathrm{b}}$ Warwick Business School, University of Warwick, Coventry, CV4 7AL, U.K.
}

Endless Leverage Certificates are long or short positions in an underlying that are partly financed with a loan from an issuing bank. The default risk for the bank is limited because the position is unwound if the underlying breaches a predetermined stoploss level. We show that the value of an ELC is virtually independent of the volatility of the underlying, and is at most $0.3 \%$ higher than its intrinsic value. We investigate several potential pitfalls of ELCs, such as the liquidity, the valuation of the instruments, and the price-impact upon unwinding. We find that ELCs are competitively priced and traded. For a sample of 5,129 ELCs issued on DAX-30 stocks we find an average bid-ask spread of $0.25 \%$ relative to the underlying value, which is significantly lower than comparable spreads on covered warrants and eoptions. We find that on average, ELC-longs (-shorts) are overpriced by $0.51 \%$ $(1.01 \%)$ relative to their intrinsic values. An intraday event study on stoploss triggers shows a pronounced increase in trading activity following stoploss events, but a negligible price impact.

\section{JEL Classification: G12, G13, G14}

Keywords: Financial Innovation, Financial Derivatives, Structured Products.

* Corresponding author, telephone: +44 (0)1865 288905. E-mail: Jos.vanbommel@sbs.ox.ac.uk. The authors thank research assistant Simon Kubbies for help with data collection, and seminar participants at the University of Bonn and the University of Karlsruhe for valuable feedback. 


\section{Introduction}

Endless leverage certificates (ELCs) are structured products engineered by European banks that are marketed to retail investors. In essence, an ELC is a levered position in an underlying security, which can be long or short. If an investor buys an ELC-long from the issuer, the latter buys, on the investor's behalf, one unit of the underlying, and finances part of the purchase with a loan. The loan, referred to as the financing level, accrues interest daily and is adjusted for dividend payments on the underlying. The interest rate on the financing level is set at a fixed spread above a riskfree benchmark such as Euribor. The issuer's position is protected by a stoploss or knockout level. As long as the value of the underlying is above the stoploss level, the security is alive, and its intrinsic value is simply the difference between the value of the underlying and the financing level. When the market price of the underlying breaches the stoploss level, the bank sells the underlying and the security holder receives the proceeds of the liquidating sale minus the financing level. Analogously, for an ELC-short, the issuer short-sells one unit of the underlying and keeps the proceeds in a designated interest accruing account. Upon breach of the stoploss of an ELC-short, the issuer liquidates the position and the holder receives the financing level minus the outlay needed to cover the short position. Investors have the right to exercise: they can order the bank to unwind the levered position before a stoploss

event occurs. Alternatively, ELC-holders can also sell their security in the secondary market, where the issuing banks are the most active market makers and post narrow bidask spreads.

ELCs have become very popular in Europe where they are marketed to retail investors under names such as Turbos, Waves, Mini-Futures or Speeders. In July 2007 there were more than 30,000 ELC contracts outstanding in Germany and the Netherlands alone, and 
the total monthly trading turnover in Germany topped $€ 9$ billion. ${ }^{1}$ ELCs are also popular in Switzerland and Austria, and have also been introduced in France, Italy, Spain and Portugal, among others.

We attribute the success of ELCs within the class of structured product to the relative simplicity of the contract. ${ }^{2}$ Despite the fact that they are derivatives, their value is virtually independent of volatility and interest rates. ELCs have a delta of unity, while their other Greeks are zero. Hence, ELCs liberate leverage seeking investors from complex option pricing formulas, implied volatilities and dividend adjustments. Because the option component of an ELC is small, investors can readily compare the intrinsic value with the price quotes to ascertain that they get a competitive deal. An advantage for the issuer is the constant hedge ratio, which makes ELCs very simple to hedge.

The most widespread structured products to date are covered warrants, which essentially are European-style option contracts written by banks. They are popular in almost all countries with an active stock exchange outside the United States. Banks write covered warrants on indices, stocks, baskets of stocks, commodities and exchange rates, among others. ${ }^{3}$ The main attraction of covered warrants is that they tend to be more liquid than regular options that originate on exchanges. For regular options, the large amount of series outstanding tends to reduce liquidity per series. For covered warrants, the issuing banks assume the role of market makers. The issuers have an incentive to make their warrants look attractive by quoting narrow bid-ask spreads. Chan and Pinder (2000) investigate warrants listed on the Australian Stock Exchange, and find that they are overpriced by up to $10 \%$ compared to the exchange issued options on the same underlyings. They explain large part of this difference to the higher liquidity of the

\footnotetext{
1 Source: websites of ABN AMRO, Commerzbank, Deutsches Derivate Institut (DDI), and Deutsche Börse. For a comparison, during the same period, the combined trading turnover of the 30 Xetra-Dax stocks was $€ 172$ billion (source Deutsche Börse).

2 The raison-d'être for the Structured Products class as a whole is that these at first sight redundant securities offer investors lower transaction costs, on set-up and liquidation, than the replicating portfolios.

3 Covered warrants are very different from corporate warrants, options on primary shares issued by corporations (e.g. as a 'sweetener' to debt issues or to raise equity finance in rights issues).
} 
warrants. Ter Horst and Veldt (2004) study a sample of 111 warrants issued on Dutch stocks and find an average overpricing of $29 \%$ vis-à-vis options. They attribute this to behavioral biases, and to the complexity of estimating the true value.

Since the start of the third millennium, a plethora of complex structured products have been introduced and marketed to retail investors under names such as guaranteed return certificates, click-funds, reverse convertibles, turbos, sprinters, double-ups, or airbags. These products offer complex payoff schedules and include multiple and exotic option features. Stoimenov and Wilkens (2005) provide a taxonomy of structured products, and report that on average structured products are overpriced by $4 \%{ }^{4,5}$ They find that structured products are overpriced by, on average, 4\%. Moreover, they report that overpricing is more severe for more complicated products, and that overpricing decreases over the life of the product. The retail market for structured products has grown dramatically in virtually all markets outside the United States. ${ }^{6}$ One explanation for the relative absence of structured products in the U.S. is the strict regulation by the SEC, which restricts the marketing of structured products on the scale that is common in the rest of the world. At the same time, trading on margin and short-selling is readily available to U.S. retail investors. Indeed, trading ELCs is very similar to margin trading.

\footnotetext{
4 The authors distinguish between combinations of plain vanilla options and products with exotic components. The most popular variations of the first category are the classic reverse convertibles (long bond, short put), corridors (long-call, short-call with $\mathrm{X}_{1}<\mathrm{X}_{\mathrm{s}}$ ), guarantee products (i.e. bond, call), outperformance products (stock, long-call, $2 \times$ short-call with $\mathrm{X}_{\mathrm{l}}<\mathrm{X}_{\mathrm{s}}$ ). In the second category we find barrier options and double barrier products.

${ }^{5}$ Other studies on complex structured products include Burth et al. (2001), who distinguish concave and convex structured products in the Swiss market and find overpricing of $2 \%$, Grünbichler and Wohlwend (2005) who compare implied volatilities of the put option component of Swiss reverse convertibles with those of EUREX options, and find primary market overpricing, which decreases in the secondary market, and Hernandez et al. (2007), who study outperformance certificates and find overpricing of $2 \%-3 \%$.

${ }^{6}$ In the 1980s index certificates, such as MICDs, SPINs and SPDRs were introduced in the U.S.. They were investigated by Chen and Kensinger (1990) and Chen and Sears (1990) and Baubonis et al (1993), who estimated that the instruments were overpriced by $2-4 \%$ upon issue and that overpricing gradually disappeared over the life of the security. In 2001, Reverse Convertibles were introduced in the U.S. by ABN AMRO. See Benet et al. (2006) for an analysis.
} 
The key difference with margin trading is that for ELCs each position has an attached margin account, for which no margin calls are made but unwinding occurs automatically when the position's leverage reaches a predetermined level.

Following the tradition of the literature, our main research question is whether ELCs are competitively priced and traded. In particular, we study three potential caveats for investors. A first worry that ELC traders may have are the bid-ask spreads that are quoted by the issuing banks in the aftermarket. We find that the spreads on ELCs are remarkably narrow. In January 2007, there were 5,129 ELCs written on the 30 Xetra DAX stocks. From quote snapshots, we find a median bid-ask spread of $€ 0.02$, or $0.68 \%$ of the value of the ELC.

To compare bid-ask spreads across derivatives, we develop a novel statistic, the leverage adjusted spread, which essentially is the bid ask spread expressed as a percentage of the underlying value that it claims. For a large sample of ELCs we find the median leverage adjusted spread to be $0.18 \%$, almost half the median leverage adjusted spread on covered warrants, which we find to be $0.30 \%$.

Consistent with market microstructure theory, we find that leverage adjusted spreads increase in various risk proxies, such as the bid-ask spread and the historic volatility of the underlying. More interesting is that bid-ask spreads decrease over the life of the security, despite the endless nature of the security. We attribute this phenomenon to time varying competition in secondary market: for young ELCs, the issuing banks are the only sellers, while for seasoned ELCs, retail investors start competing in the limit order book. Consistent with this the time pattern in spreads, we also find that pricing errors relative to intrinsic values decrease in the age of the security.

A second danger for ELC-investors is that the security may be overpriced vis-à-vis the risk adjusted theoretical value. Overpricing can be due to the interest rates that issuers charge on the financing levels. These interest rates are set at a predetermined riskfree benchmark such as Euribor or EONIA plus a credit spread. The credit spread, typically 200 basispoints, is fixed over the life of the security. This average spread seems high for the seemingly low risk for the issuing banks. 
However, because ELC-holders have the right to exercise, a lower bound for the value of an ELC is its intrinsic value. Apart from the right to exercise, ELC-holders hold a valuable default put option: if the price of the underlying precipitates through the stoploss and the financing level in one swift movement, the ELC-holders' loss is limited while the bank suffers a default on the loan. Our finding that the observed premium increases in risk-proxies suggests that the limited liability option is indeed appreciated by the market.

To gauge whether market prices are fair, we derive a value function for ELCs. We show that an ELC has an optimal exercise level which increases at the same rate as the financing level. Or, in equilibrium, an ELC should be alive as long as the value of the underlying lies between the observable stoploss level and an unobservable optimal exercise level. In this region the value of the ELC is higher than its intrinsic value. The optimal exercise level can be found from the trade off between the value of the default put and the cost of the credit spread on the financing level.

To estimate the ELC-values, we develop a Monte-Carlo algorithm that uses historical returns to find expected payoffs under different exercise strategies. Our analysis shows that an ELC-long on an average Xetra-DAX stock with financing level of $€ 100$ and a stoploss level $€ 105$, has an optimal exercise level of $€ 106.20$. The maximum value of the option component is approximately $€ 0.005$, or $0.1 \%$ of the value of ELC. ${ }^{7}$ For ELCshorts the maximum value of the option component is $0.3 \%$ of the intrinsic value.

Empirically, we find, for a sample of 25,645 quote snapshots, an average midprice premium over the intrinsic value of $0.51 \%$ for ELC-longs and $1.00 \%$, suggesting that the average overpricing is less than $1 \%$. Expressed as a percentage of the underlying it claims, the average midprice premium over intrinsic value is $0.14 \%$ for ELC-shorts and $0.20 \%$ for ELC-longs.

A third potential pitfall for investors is the fairness of ELC terminations. Upon breach of a stoploss level, the issuer unwinds the position and returns the residual value to the ELC

\footnotetext{
${ }^{7}$ The maximum is reached when the value of the underlying is $€ 105.25$, so that the intrinsic value of the ELC is $€ 5.25$.
} 
holder. Most issuers publish residual values on their websites. We find that, on average, the underlying is liquidated $0.21 \%$ beyond the stoploss level. This shortfall is not necessarily unfair. It may be due to discontinuous trading or to the average price jump that triggers the stoploss. Moreover, the loss on unwinding may be aggravated by a market inefficient price impact.

To further gauge the fairness of ELC terminations, we conduct an intraday event study on all German stock ELC terminations from August until October 2006. Interestingly, we find a significant increase in trading activity around the stoploss breach. For stoploss events of ELC-shorts we also find a discernable price impact, of approximately $20 \%$, immediately following the trigger. For ELC-longs we find no such price impact.

To our knowledge, ELCs have not yet been widely investigated, despite the growing relevance for these structured products. In earlier paper, Entrop, Scholz, and Wilkens (2007) find that ELCs may be overpriced by up to $25 \%$. In contrast to us, they assume that the underlying follows a continuous price process with no trade interruptions so that there is no default risk for the bank. Subsequently the bank's profit potential increases without bound - in the investors' holding period. We argue that the bank's position is not risk free and derive an optimal holding period in terms of the value of the underlying. Our value function gives an equilibrium price, which is dependent of the assumed return distribution and does not rely on investor irrationality.

In the next section we describe the ELC market in greater detail and discuss our sample. In section III we assess the bid-ask spreads in the secondary market. In section IV we develop a valuation function for ELCs, and conduct a Monte Carlo procedure to estimate the value of the option value of a typical ELC. Section V investigates ELC mid-prices, compared with intrinsic values. In section VI we look at residual values and study the price impact on termination. Section VII concludes.

\section{ELC terminology and data description}

We define ELCs as securities that are open-ended, and have intrinsic values in the form of $|S-D|$, where $S$ is the value of the underlying and $D$ is a financing level which increases at a well specified interest rate, $r_{D}$, that is set at a constant spread over a risk free 
benchmark. Financing levels should be protected by a stoploss level, denoted $K$, so that if the underlying breaches the stoploss level, the issuer automatically terminates the contract and pays the ELC holder a residual value. Any dividends paid by the underlying should accrue to the financing level. ${ }^{8}$

Figure 1 gives the payoff- and value-diagrams for ELCs. The payoff occurs upon exercise or through a stoploss event. It is bounded below by zero. This limited liability option gives an ELC a value that is slightly higher than its intrinsic value. Notice that in Figure 1 we exaggerate the option component of the ELC, to make the payoff and value diagrams distinguishable. We shall later see that the option value is very small.

----- Figure 1 around here ----

The ELC is the successor of the Turbo-certificate, an instrument with maturity date and a fixed financing and stoploss level. ${ }^{9}$ Although the first ELC contract can be traced back to 2001, they have become particularly popular since 2004. Figure 2 illustrates the success of ELCs. From Panel A we see that the number of outstanding ELC contracts in Germany and the Netherlands has doubled in 2006. From Panel B we see that the major players are Commerzbank and ABN AMRO, who both claim the product's invention, and that fifteen other players are competing for a share of the growing ELC market. Panel $C$ shows market shares by types of underlying. We see that although $65 \%$ of all ELCs that were outstanding in the last quarter of 2006 were written on stocks, $65 \%$ of the trading turnover comes from index ELCs.

----- Figure 2 around here ----

Banks periodically issue bundles of ELCs to themselves on the back of a comprehensive base prospectus and a brief final terms sheet. Table 1 gives an overview of the main

\footnotetext{
${ }^{8}$ This means that on ex-dividend day, the financing level of an ELC-long (-short) is adjusted downward (upward) by the dividend amount. This feature makes the ELC independent of dividend yield or dividend payment dates. This construction is similar for Australian "endowment warrants", covered warrants for which the strike price is reset upon dividend payment. See Brown and Davis (2004) for an analysis of these products.

${ }^{9}$ Essentially, Turbo-certificates charge interest upfront, for a predetermined maximum length of the loan. See Schulz, Baule and Wilkens (2004) and Muck (2006) for an analysis of Turbo-certificates.
} 
contract specifications for the eight largest issuers in the German market. We see that issuers market their ELCs under different names, and that credit spreads and other characteristics vary across banks. Most issuers adjust the stoploss levels $K$ once a month, some issuers adjust $K$ daily. ${ }^{10}$

The adjustment of $K$ is to a large extent at the issuer's discretion. In general, $K$ moves at the same rate as $D$, but monthly instead of daily. However, most issuers reserve the right to set the knockout level further from the financing level if they feel that the perceived risk of the underlying has increased. Some issuers specify a range for the stoploss premium, $|K-D| / D$. Many issuers bestow their ELCs with a ratio, which refers to the number of underlying units per certificate. Ratios are chosen by the bank to arrive at particular price ranges. ${ }^{11}$

----- Table 1 around here ----

When an issuer sells an ELC-long (-short), it immediately buys (short-sells) the underlying to hedge its position. Upon breach of the stoploss level of an ELC-long, the issuer sells the underlying and returns the proceeds of the liquidating sale minus the current financing level to the ELC holder. When an ELC-short is knocked out, the issuer buys the underlying with the financing-level to cover the ELC's short position, and returns the residual to the ELC-holder. Issuers specify this unwind procedure in detail in the base prospectus and often specify minimum residual values based on the minimum (or maximum, for ELC-shorts) market price of the underlying in a specified event window around the stoploss event. All issuers publish a list of terminated ELCs and their residual values on their websites so that investors can verify that the residual value is

\footnotetext{
${ }^{10}$ Monthly adjustment is the norm. Because of this, $K$ often becomes the focal characteristic to identify an ELC. Although ELCs have 12-character ISIN-codes, brokers and traders refer to them with their stoploss level, e.g. "Porsche Turbo 806.00" or "Speeder BMW 46.10".

${ }^{11}$ E.g. a bank may have a policy to 'aim' for low prices. E.g. an ELC-long with financing level €24 on a stock which trades at $€ 30.30$, may be divided into one "Mini-future" trading at $€ 6.30$ by one bank or 10 "Speeders" of $€ 0.63$ by another bank.
} 
fair. ${ }^{12}$ In general, cash settlement occurs within a week of the stoploss event. Apart from a stoploss breach, ELCs may be terminated if the holder exercises or if the issuer calls. Both scenarios lead an unwind procedure similar to a stoploss breach.

Issuers discourage exercising ELCs by stipulating cumbersome procedures or lags. Two issuers stipulate that ELCs can be exercised once a year, for three other issuers the exercise opportunity occurs once a month. Even the issuers that allow daily exercise, stipulate conditions such as a written notice sent by fax. The result is that investors generally prefer to sell instead of exercise, especially because issuers post bid-prices that are very close to (and are often higher than) the intrinsic value. When the issuer buys back an ELC, its position becomes neutral. We therefore view selling and exercising as equivalent. In the prospectuses, issuers usually indicate that they reserve the right to unilaterally terminate, or call, the contract if hedging becomes difficult or impossible, and specify disruption events (such as takeovers, restructurings, or threats thereof) when an ELC can be called.

----- Table 2 around here ----

Since short-selling is not allowed (for bets against the underlying investors can buy ELCshorts), the first trades after an ELC-issue are predominantly buys. After issuance the sponsoring bank becomes the most active market maker. The aftermarket is a focal venue of competition between the different issuers, causing bid-ask spreads to be relatively narrow. Issuers also compete on other characteristics. Table 2 illustrates the differences in ELC characteristics marketed by the eight largest issuers of stock-ELCs during our sample period in January 2007. Apart from quoting low credit spreads and narrow bidask spreads, issuers make their ELCs attractive by issuing them at high levers (defined as $S / S-D \mid)$ and low stoploss premiums. During our sampling period, Bank $C$ issued ELCs with relatively high levers and low average stoploss premiums. They charged the lowest credit spreads on the financing levels, and quoted narrow bid-ask spreads. These competitive features made Bank C's ELCs the most actively traded, at least in January

\footnotetext{
${ }^{12}$ The detail of residual value reporting varies. Some issuers only disclose the ISSN numbers and residual values, while others give the stop-loss and financing levels, as well as the termination date or even the time, to the second.
} 
2007. When Bank $B$ entered the market they issued even more aggressive ELCs, as gauged by their levers and stoploss premiums. Apart from differentiating their ELCs on product characteristics, issuing banks also market their products aggressively using internet banners and newspapers ads. The typical tagline emphasizes the leveraged returns, the limited liability, and the endless nature of the product, e.g. "Big opportunities with small stakes." "Unlimited upside, limited downside"13

\section{The bid-ask spread in the secondary market.}

In this section we investigate the liquidity of ELCs. We collect snapshot quotes from German Internet broker www.cortalconsors.de, and their Netherlands based colleague www.binck.nl, who both provide real time quotes for substantially all structured products available to German and Dutch retail-investors. We only consider structured products on the 30 Xetra-DAX stocks and the 25 AEX stocks. ${ }^{14} \mathrm{We}$ complement the quote data with the relevant ELC-characteristics, which we collected from the issuers' websites. In total we take five quote snapshots during morning trading hours on different working days in January 2007 for 5,129 Dax-underlying and 444 AEX-underlying ELCs. For comparison, we also take 20 contemporaneous snapshots of bid and ask quotes of their underlying securities and five snapshots of 18,003 covered warrants ("Optionscheinen" in German) written on Xetra-DAX stocks, and 6,141 option contracts on AEX stocks that were outstanding during our sampling period.

----- Table 3 around here ----

Table 3 gives the comparative statistics of the bid-ask spreads. For the German market, the average ELC bid-ask spread is $€ 0.049$, or $0.977 \%$ of the security's midquote, which is significantly lower than the average spread for covered warrants. We also compute the

\footnotetext{
${ }^{13}$ On the Goldman Sachs website we read "Large chances with limited stakes. With Mini-futures investors can accelerate price developments. The volatility does not affect the value. The lifespan is unlimited." ("Grosse Chancen bei kleinem Kapitaleinsatz. Mit Mini-futures nehmen Anleger ueberproportional an der Kursentwicklung des Basiswerts teil. Die volatilität hat keinen enfluss auf den preis der Mini-Futures, die Laufzeit ist unbegrenzt.")

${ }^{14}$ ELCs are also offered the most liquid madcap stocks and on foreign stocks (including large American firms such as Microsoft or Google).
} 
spreads per unit of underlying, by multiplying the gross spread by the derivatives' ratio and hedge ratio. We denote these the leverage adjusted spreads. For ELCs, the average absolute and relative leverage adjusted spreads are $€ 0.17$ and $0.24 \%$ respectively. The leverage adjusted spreads for covered warrants are more than twice as high. This provides strong evidence that the secondary market for ELCs is at least as competitive as the market for covered warrants. The spread pattern is mirrored in the Dutch market, even though we find $€$-spreads to be smaller, and proportional spreads to be higher, on average. These differences are mostly due to the different average denominations.

Nevertheless, the leverage adjusted spreads on ELCs are still about four times higher than the spreads on the underlying, suggesting that for unconstrained investors in a transaction cost free world, it would be cheaper to trade directly in the underlying. We attribute the difference between ELC spreads and underlying spreads mainly to the administration, hedging and listing costs. For investors, transaction costs are mostly proportional of transaction value. In a world with transaction costs, buying ELCs is likely to be cheaper than opening a position in the underlying. ${ }^{15}$ In addition, the increased spreads may also be due to a higher adverse selection that in the ELC market. Biais and Hillion (1990) and Chan et al. (1995) suggest that resource constrained informed investors are more likely to liquidate their informational advantage in the derivative markets than in the market for the underlying.

To better understand the determinants of the bid-ask spread on ELCs we regress the proportional leverage adjusted spreads on several ELC-characteristics. The results of this analysis are given in Table 4. We see that spreads increase in the contemporaneous bidask spread on the underlying, the stoploss premium, and the volatility of the underlying. Interestingly, there is no strong evidence that the leverage adjusted spread increases in the lever. This suggests that any increased adverse selection costs in the high gearing segment is offset by decreased transaction costs, perhaps due to economies of scale. ${ }^{16}$

\footnotetext{
${ }^{15}$ This is the case as long as the ELC's lever is higher than four. In this case the increased bid-ask spreads is more than offset by a reduction in the transaction fees.

${ }^{16}$ Although we have only limited turnover data, industry sources told us that trade is concentrated in high lever ELCs.
} 
The positive coefficient on the stoploss premium suggests that this ELC-characteristic is a risk-proxy. Indeed, issuers indicate that they set higher stoploss levels for riskier stocks. When we include issuer-, day-, and underlying-dummies in the regression, the positive coefficient on the stoploss premium vanishes. The most interesting finding of Table 4 is that age affects the observed bid-ask spreads. Although ELCs are endless, and age does not affect the fundamental value of the security, bid-ask spreads decrease by approximately $0.10 \%$ for each additional year of age. This finding is reminiscent of lifecycle mispricing that has been documented for closed end mutual funds and other structured products (Weiss, 1989; Peavy, 1990; Stoimenov and Wilkens, 2005). We attribute this effect to the increase in secondary market competition. Upon issuance of a new ELC-series, the issuer is the monopolist buyer and seller, but as ELCs become more seasoned, the issuer is likely to receive competition in the limit order book, especially on the sell-side. ${ }^{17}$

\section{Valuing ELCs}

To gauge whether the return on ELCs is commensurate with their risk, we need to value the instrument. There are two main difficulties with this task. First, we have to deal with the complex option component of the ELC. Second, we need to account for the kurtosis and discontinous trade that characterize the underlyings' returns.

In this section we offer a first attempt to value a typical ELC. First, we decompose the instrument into four components:

$$
E L C=|S-D|-P V(\text { credit spread })+\text { Default Put }+ \text { Exercise Put }
$$

The first part, the absolute difference between the value of the underlying and the financing level, is the intrinsic value. The second part is the present value of the credit spread. This riskless cashflow stream accrues to the issuer. The value of this component depends on the expected time until knockout. In exchange for the credit spread, the ELC-

\footnotetext{
${ }^{17}$ ELCs are traded on limit order book trading platforms, where retail investors can improve on the market makers' quotes.
} 
holder obtains two options. First, the ELC contains a Default Put which gives the holder the right to put the underlying to the bank in exchange for forgiveness of the loan. This option is valuable if there exists a positive probability that the underlying precipitates through the financing level before it is knocked out, leaving the issuer with a loss. Second, the ELC holder has holds an exercise put. This option gives the holder the right to exchange the security for the intrinsic value at any time before knockout.

Due to the latter option, the intrinsic value is a lower bound for the ELC value. The reason for this is that if we would have $P V$ (credit spread) $>$ Default Put, the holder would exercise the Exercise Put and claim the intrinsic value. If the underlying follows a sufficiently smooth process, and if it is continuously traded in a market with sufficient depth, the value of the default put is zero, so that the intrinsic value is also the upper bound for the ELC-value. Or, exercisable ELCs on 'jump-free', continuously traded underlyings should not exist in an otherwise frictionless world, and if they do exist, they offer arbitrage profits to the issuing banks. Entrop et al. (2007) take this view and assume that ELC-holders exercise suboptimally. Naturally, the later the holders exercise, the larger the profits for the bank. If the holders never exercise, and hold the ELC until knockout, the expected profit to the bank is infinite.

We know however that underlying securities do not follow smooth processes and are not continuously traded. Default events can occur intraday, upon a dramatic instantaneous jump in the value of the underlying, or overnight, when there is no trade. In the following we derive a value function for the option component of an ELC under the following simplifying assumptions:

Assumption 1: A trading day has two periods: daytime, when there is continuous trade and the price follows a smooth process between an opening and a closing auction, and overnight, when there is no trade.

Assumption 2: There are no transaction costs, and there is no price impact. The unwind procedure triggered by a stoploss or exercise event is frictionless and immediate. 
Assumption 3: The financing- and knockout levels are constant during the trading day and are reset every morning at the opening auction. Both levels increase at the same constant rate: $r_{E L C}=\ln \left(\frac{D_{t+1}}{D_{t}}\right)=\ln \left(\frac{K_{t+1}}{K_{t}}\right)$.

Assumption 4: The default risk is non-systematic.

Assumption 5: The issuer will not unilaterally unwind ("call") the security.

Assumption 6: The ELC holder exercises so as to maximize the value of the security.

Our assumptions closely reflect industry practice. Assumption 2 implies that we do not consider the issuer's option to pay the minimum possible residual value given the conditions in the prospectus. From table 1 we know that most ELC-contracts specify a guaranteed minimum residual value, typically based on the lowest stockprice within a time interval (often three hours) after the stoploss trigger. In the next section we document evidence that issuers do not systematically pay the contractual minimum residual value, and unwind on a best-efforts basis. Similarly, assumption 5 states that banks do not opportunistically call, even though it may be optimal if the value of the underlying approaches the stoploss level. Empirically, we do not find any terminations near $K$, consistent with our assumption. We attribute the bank's commitment to not opportunistically call ELCs to the repeated game nature of the business. Clearly, in a one shot game, the equilibrium value is simply the intrinsic value $|S-D|$ : if the value were higher, the issuer calls, and if the value were lower, the holder exercises.

Notice that if banks do behave opportunistically, the option component is less valuable than indicated by our estimation. Assumptions 1 and 4 on the other hand negatively bias our estimate: clearly, the existence of daytime jumps and systematic risk increases the value of the default put, and hence of the ELC.

In assumption 6, we conjecture that there is an optimal exercise level. Every evening, ELC-holders can decide to exercise the security. If they keep the security alive, they essentially buy an overnight limited liability option (the default put) which limits their loss (vis-à-vis holding the underlying directly) in case the underlying precipitates through the financing level during the night. The price they pay for this downside protection is the overnight credit spread on the financing level. Clearly, the greater the distance between $S$ 
and $D$, the lower the value of the default put. Because the credit spread is constant, we conjecture that if the underlying reaches some optimal exercise level $E^{*}$, the credit spread no longer justifies the value of the default put, leading rational ELC-holders to exercise.

Hence, if the underlying trades between $K$ and $E^{*}$, the true value of the issuer's position, which we denote $L(S)$ (for loan), is lower than its facevalue value $D$. In a frictionless market, a rational ELC-holder exercises as soon as the true value of the loan is higher than its face value. The optimal exercise level $E^{*}$ is thus given by the value of the underlying for which we have $L(S)=D$. Because the financing level does not accrue interest during the day, it is optimal for the holder to make her exercise decision at the end of trading day, at the closing auction.

In the following, we let $S_{t}^{\prime}$ and $S_{t}^{\prime \prime}$ denote the value of the underlying at the opening and closing auction of trading day $t$ respectively. Similarly, we let $L^{\prime}\left(S_{t}^{\prime} \mid D_{t}, K_{t}, E_{t}^{*}\right)$ and $L^{\prime \prime}\left(S_{t}^{\prime \prime} D_{t}, K_{t}, E_{t}^{*}\right)$ stand for the true value of the financing level during the opening and closing auction. The overnight riskfree rate is given by $r$. The probability distribution of the next day's opening price, $S_{t+1}^{\prime}$, conditional on $S_{t}^{\prime \prime}$, is denoted $\psi\left(S_{t+1}^{\prime}\right)$. If during the closing auction of day $t$, the holder does not exercise the ELC, the value of the financing level is given by:

$$
L^{\prime \prime}\left(S_{t}^{\prime \prime} \mid D_{t}, K_{t}, E_{t}^{*}\right)=e^{-r}\left(\int_{0}^{D_{t+1}} S_{t+1}^{\prime} d \psi\left(S_{t+1}^{\prime}\right)+\int_{D_{t+1}}^{K_{t+1}} D_{t+1} d \psi\left(S_{t+1}^{\prime}\right)+\int_{K_{t+1}}^{\infty} L^{\prime}\left(S_{t+1}^{\prime}\right) d \psi\left(S_{t+1}^{\prime}\right)\right)
$$

The first integral refers to the states of the world where the loan defaults, and the bank recovers $S_{t+1}^{\prime}<D_{t+1}$. The second integral refers to the states where the ELC is knocked out and the loan is fully recovered. The integrant in the final integral denotes the value of the loan at the opening auction of the following day if the ELC is not knocked out overnight. We now let $\pi\left(S_{t}^{\prime}\right)$ denote the probability of a knockout during daytime, and let $\mathscr{Y}\left(S_{t}^{\prime \prime}\right)$ stand for the probability distribution function of the closing price conditional on $S_{t}^{\prime}$ and on not seeing a daytime stoploss. The value of the financing level at the opening auction is then: 


$$
L^{\prime}\left(S_{t+1}^{\prime} \mid D_{t+1}, K_{t+1}, E_{t+1}^{*}\right)=\pi\left(S_{t+1}^{\prime}\right) D_{t+1}+\left(1-\pi\left(S_{t+1}^{\prime}\right)\right)\left(\int_{K_{t+1}}^{E_{t+1}^{*}} L^{\prime \prime}\left(S_{t+1}^{\prime \prime}\right) d \vartheta\left(S_{t+1}^{\prime \prime}\right)+\int_{E_{t+1}^{*}}^{\infty} D_{t+1} d \vartheta\left(S_{t+1}^{\prime \prime}\right)\right)
$$

The first term on the right hand side refers to a daytime knockout. Due to continuous trading and sufficient market depth, the issuer recoups the loan in its entirety. The second term conjectures that the ELC-holder keeps the ELC alive if the stock closes below $E_{t+1}^{*}$, and exercises otherwise. In the later event, the bank recovers the loan's face value, $D_{t+1}$. Notice that we do not discount the closing payoffs. This is because the effective daytime interest rate is zero. ${ }^{18}$ In equilibrium, ELC-holders exercise if the value of the loan reaches its face value. Hence, $E_{t}^{*}$ solves:

$$
L^{\prime \prime}\left(E_{t}^{*} \mid D_{t}, K_{t}, E_{t}^{*}\right)=D_{t} \quad \forall t
$$

It immediately follows that if the daytime and overnight return distributions are stationary, $E_{t}^{*}$ increases together with $D_{t}$ and $K_{t}$, at $r_{E L C}$.

Unfortunately, the system of equations (2)-(4) cannot be solved analytically, due to repeated integration. Therefore we recur to a Monte Carlo simulation to find the exercise levels and values for several ELCs.

From Datastream we collect 15 years worth of historical intraday return data for all Xetra-DAX stocks. In total we have 97,288 days of open-low, open-high, low-close, high-close and close-open returns. Because the value of the option component is very sensitive to extreme outcomes, we pool the data to model a "typical" DAX-stock. ${ }^{19}$ The return distributions of both the daytime and overnight returns are significantly leptokurtic, with the kurtosis of the overnight return being particularly severe, at 142.87 . Moreover, the overnight returns are positively skewed. Figure 2 illustrates the empirical distribution of the daytime and intraday returns.

\footnotetext{
18 This is because central banks levy interest rates, and apply reserve requirements, on overnight deposits.

${ }^{19}$ In an earlier version of this paper we valued ELCs for each underlying. We found a large disparity between values. I.e., due to a single negative overnight return of $-59 \%$ in its history, we found one stock's ELCs to be significantly underpriced. Another stock did not have any overnight returns of lower than 5\% in the last 15 years, hinting that any ELC on this stock would be overpriced.
} 
We standardize our ELCs to have $D=€ 100$, and evaluate ELC-values for different credit spreads and different stoploss values $K$. Each simulation occurs in two stages. First we search for the optimal exercise level $E_{t}^{*}$ by evaluating the evening value with $S_{t}^{\prime \prime}=E_{t}^{*}$ and look for the $E_{t}^{*}$ so that the average payoff for the bank over 100,000 ELC-runs just equals $D$. Then we evaluate the evening value for other $S_{t}^{\prime \prime} \in\left(K_{t}, E_{t}^{*}\right)$.

In our simulation we assume that all historic return observations are equally likely, and hence that there is no autocorrelation in the first or second moment. For every ELC run, we randomly select, with replacement, an open-low/low-close return combination from all intraday returns, and an overnight return from all historic overnight returns. We do this until the ELC terminates through either a stoploss or exercise. See appendix for the actual algorithm used.

Figure 3 gives the estimated value of the option component for six ELCs on the hypothetical typical DAX-stock. We find that the value of the option component first increases and then decreases over the range where the ELC is alive. This pattern can be explained by the fact that the two options offset each other: when the value of the default put is high, the option to exercise is low, and vice versa.

----- Figure 3 -----

Our simulations suggest that an ELC-long with a typical stoploss premium of 5\% and typical credit spread of 200 basispoints, written on a typical DAX stock, has a value that is always less than $€ 0.005$ higher than its intrinsic value. This typical ELC-long has an optimal exercise level $€ 106.40$, which means that it should be alive only if the underlying trades in the region $S \in(€ 105, € 106.40)$. We find the expected life of this ELC to be 1.4 days, maximum. ${ }^{20}$ Not surprisingly, ELC values, feasible regions and life-spans are larger for lower credit spreads and lower stoploss premiums. Consistent with observed prices, we find that the option component of ELC-shorts is significantly higher than that of ELC-

\footnotetext{
${ }^{20}$ This maximum obtains when the stock trades at $S=€ 106.0$. The maximum lifespan for the ELC-short with $K=96.23$ and credit spread of 200 basispoints is 4.8 days. It obtains when $S=€ 90.9$.
} 
longs. We attribute this difference to the skewness of the overnight return distribution. Of our 97,288 historic overnight returns, 229 were higher than 5\%, while 175 were lower than $-5 \%{ }^{21}$

From our simulation we also find that the default probability of an ELC-long financing level that is collateralized by a typical DAX stock with a stoploss premium of $5 \%$ is approximately $0.4 \%$. In case of default, the recovery rate is approximately $97.8 \%$. The default probability on a ELC-short financing level is approximately $1.7 \%$, and the recovery rate $97.9 \% .^{22}$

The most important observation however is that we find the option value to be very small compared to the value of the ELC. In the interval where the option component is valuable, the ELC value is at least $€ 5.00$, implying that the option value is at most $0.1 \%$ of the value of the ELC.

\section{Price and Intrinsic Value}

The small value of the option component makes ELCs attractive to investors, because they can easily ascertain the instruments' values by computing the intrinsic value. Because ELC-investors can exercise their securities and claim the intrinsic value at a relatively low cost, we expect market prices to be bounded below by their intrinsic values. This prediction is borne out by the data. For our sample of 5,573 German and Dutch ELCs, we compute the differences between the midquotes and their intrinsic values, based on contemporaneous midquotes for the underlying. We find an overall average absolute premium of $€ 0.019$ and an average relative premium of $0.63 \%$. We find premiums to be significantly higher for ELC-shorts. The overall premium pattern is similar for Germany and the Netherlands, see table 5.

----- Table 5 around here ----

\footnotetext{
${ }^{21}$ For even higher absolute returns the skew switches: There were 23 overnight returns that were higher than $10 \%$, while 27 returns were lower than $-10 \%$. Apparently the skew of absolute returns higher than $5 \%$ is more important than the extreme tails, at least for ELCs with stoploss premiums of 5\% or less.

${ }^{22}$ The estimated default probabilities are the relative frequencies of ELC-defaults in our simulation. Default probabilities and recovery rates also depend on $S$. The values given are averages over the feasible region.
} 
From Table 5 we see that the economic significance of the observed premiums over intrinsic value are small. However, the statistical difference between theoretical and observed premiums is significant. This is illustrated in Figure 4, which scatters the actually observed premiums, rescaled as if they belonged to ELCs with $D=€ 100$. In lower part of the diagram we plot the theoretical premium for typical DAX stock ELC with a stoploss premium of $3.5 \%$ and a credit spread of 200 basispoints, as computed in the previous section.

----- Figure 4 -----

If we look at the range of levers in our sample of observed snapshots, we see that approximately $95 \%$ of all listed DAX stock ELCs had their underlying trading beyond the optimal exercise level. This hints that many ELC-traders may exercise (or sell) their securities too late. ${ }^{23}$ As we saw in the previous section, the significantly positive average premium over the intrinsic value is not necessarily mispricing. After all ELC consists of two valuable options. First the ELC comes with a Default Put that offers investors limited liability, in case the underlying precipitates through the stoploss and financing level in a single price jump. Second, ELCs give their holders the right to exercise the contract. Due to these options we expect ELC-premiums vis-à-vis their intrinsic values to increase in the volatility and in the lever, which is a measure of the option's moneyness. We also expect the stoploss level to affect the ELC-premium. This is because ELCs with stoploss levels closer to their financing levels can attain higher levers, making the option component more valuable. On the other hand, the stoploss level is chosen endogenously by the issuer. Banks mention in their prospectuses that they set higher stoploss levels for riskier stocks. To gauge how the main ELC characteristics affect ELC prices we carry out

\footnotetext{
${ }^{23}$ Notice that we cannot say much about the percentage or amount of late exercises. First because individual stocks have return distributions that are different from the average distribution on which we based our calculations. Second, we do not know how many contracts of each listed ELC-series are outstanding. Industry sources tell us that the open interest dramatically increases in the lever, which suggests that ELC-holders exercise according to theory: when the underlying goes their way.
} 
several regressions with as independent variable the ELC premium scaled by the value of the underlying. ${ }^{24}$ Table 6 shows the results of this analysis.

Table 6 around here ----

From Table 6 we observe that, consistent with option pricing theory, premiums are higher for ELCs written on more risky stocks. Surprisingly, we do not find a positive coefficient on the lever. We explain this by the fact that, due to the stoploss level, all ELCs are automatically "in the money". Moreover, we suspect that competition among issuers is higher in the high-lever segment of the market. This may offset the theoretical positive relationship between lever and option value. The coefficient on the stoploss premium is significantly positive, but only when we do not include underlying dummies in the regression. This finding suggests that stoploss premiums are risk proxies. Option theory predicts a negative coefficient on the stoploss premium, when we control for underlying dummies. However, regression models III and IV return insignificant positive coefficients. We attribute our failure to find significant negative coefficients to the lack of sufficient cross-sectional variation in stoploss premiums.

We also regress the premiums on the age of the instrument. Consistent with the spread pattern reported earlier, we find a negative relationship between ELC premium and age, consistent with an over time increasing competition in the limit order book.

\section{Residual value and price impact upon unwinding}

A final concern for investors is the fairness of ELC terminations. As mentioned, when an ELC breaches its stoploss level, the issuer unwinds the hedge position and returns the proceeds of the liquidating sale minus the financing level to the ELC holders. Issuers publish the residual values of their terminated ELCs on their websites. To gauge whether these terminal values are fair, we collect residual values of ELCs that were knocked out during the period January 2006 until May 2007, and for which financing and stoploss values were available. Our final sample consists of 1,801 residual values obtained for the

\footnotetext{
${ }^{24}$ If we scale by the value of the intrinsic value, we find a significantly positive relationship between the scaled premium and the lever. This relationship is mechanical due to the inverse relationship between the lever and the intrinsic value.
} 
four banks that report $D$ and $K$ alongside the residual values. Using Datastream data, we ascertain that all residual values concern stoploss triggers. ${ }^{25} \mathrm{We}$ compute the residual value shortfalls as the difference between the reported residual value and the theoretical stoploss value $|K-D|$, multiplied by the ratio. In table 7 we report the distribution of the residual value shortfalls for the entire sample and several subsamples.

\footnotetext{
${ }^{25}$ We discarded nine terminations that were triggered by an impending takeover, and five that were called after a sharp price change. Fourteen ELCs were terminated when they were deep in the money. We suspect that these were called because they had too few contracts outstanding to justify a stock market listing.
} 
Our data includes five financing level defaults, all triggered by the same event. On May $4^{\text {th }} 2007$, Pharmaceutical company Altana booked an overnight return of $33.15 \%$ and knocked out five ELC-shorts, all of which resulted in a loss for the issuer. ${ }^{26}$ The ELClong that came closest to a financing level default was written on Deutsche Telekom. On 9 August 2006, when the stock closed at $€ 12.05$, an ELC with ratio 10 had a $D$ of $€ 10.83$ and $K$ of $€ 11.70$. On August $10^{\text {th }}$, the stock opened at $€ 11.20$. During the day the stock quickly dropped to $€ 10.90$. Three days later, the ELC-holders received a residual value of a $€ 0.02$, a mere $23 \%$ of the theoretical stoploss value. ${ }^{27}$

When measured with respect to the stoploss value, the average residual value shortfall in our sample was 3.2\%. At first sight, this seems a large loss for the ELC-holders. However, ELCs are knocked out when their levers are at their highest. We find that the average shortfall with respect to the underlying was only $0.24 \%$. This shortfall may simply be explained by the average price movement that triggered the stoploss. Our finding that in over half of the cases ELC-investors received exactly the theoretical stoploss value and that $8.7 \%$ of residual values were in fact higher then their theoretical stoploss values suggests that the residual values are fair. Our finding of residual value shortfalls being slightly higher for ELC-shorts may be explained by larger upward jumps, or a price impact that is larger for unwind buys than unwind sales, possibly due to larger average open interest for ELC-shorts, or a more aggressive unwinding by the issuer.

To gauge how much of the average shortfall can be explained by discontinuous trading we divide our sample into overnight and daytime triggers. Not surprisingly, we find that residual value shortfalls for ELCs triggered overnight to be significantly higher. Panel B of table 7 shows that the residual value shortfall is approximately three times larger for overnight stop-loss events. We also check whether there are differences in residual value

\footnotetext{
${ }^{26}$ The event was driven by dividend capture. On the day before the stoploss event, Altana closed at $€ 46.50$, down $8.7 \%$. The next day, the stock started trading net of a special dividend of $€ 34.80$. The stock opened at $€ 16.99$ and reached a daily high of $€ 20.90$. Because the short seller is required to pay the dividend in full, the stock booked an overnight return of $33.15 \%$.

${ }^{27}$ This implies that the bank unwound the position at an average price of $€ 11.03(€ 10.83+10 \times € 0.02)$.
} 
shortfalls between banks. Although we find differences, F-tests cannot reject that the banks' average shortfalls have different means. The differences in standard deviations and the percentages of zero shortfalls are statistically significant but may be due to a different mix of underlying securities or ratios.

Apart from the stoploss triggering price jumps, the residual value shortfalls may also be due to a price impact that comes with the unwind transactions. Moreover, if a significant price impact obtains, it is not inconceivable that the stoploss event is anticipated by arbitrageurs who front-run the stoploss event. If there is an expected price impact, arbitrageurs could potentially profit by (short-)selling the underlying when it is trading within a few ticksizes from the stoploss level, triggering a knockout, and simultaneously submitting a limit buy (sell) order for just under (above) the stoploss level. From Table 7 we find that such an arbitrage profit could be, on average, $0.24 \%$ of the position taken in the underlying security. Which is probably not enough to cover transaction costs. Alternatively, it is conceivable that the issuing banks themselves drive the price through the stoploss level over the last couple of tick-sizes before knockout. To investigate the price dynamics around stoploss events, we conduct an event study on intraday data.

We analyze the intraday trading behaviour around the stoploss triggers of 226 ELCs written on 42 German stocks during August, September and October $2006 .{ }^{28}$ For these stocks we obtain intraday market data from the Capital market database maintained at the University of Karlsruhe.$^{29}$ We compile time-stamped price and quantity data for all trades during the sample period. For every second in the six-hour window around the trigger event, we record the last traded price and the volume during the second. We divide prices by the stoploss level, multiply them by $€ 100$, and take the average across events. Trading volumes are expressed in euros, and divided by the average volume per second for the day, then averaged across events. Both series are plotted in Figure 5 for 82 ELC-long triggers and 144 ELC-short triggers.

\footnotetext{
${ }^{28} \mathrm{We}$ considered stoploss events reported by six ELC-issuers. For these banks we also found, from their residual value webpages, 29 overnight triggers, 10 erroneous trigger announcements and 7 ELCs that were called. We discarded 12 trigger events that occurred during the first 10 minutes of a trading day.

${ }^{29}$ See http://fmi.fbv.uni-karlsruhe.de/ for further information regarding this database.
} 
In panels $\mathrm{A}$ and $\mathrm{B}$ we observe a highly significant trend in the direction of the stoploss level before the event. Such a pattern is fully expected because only the stocks that eventually breach the stoploss are included in the sample. To gauge whether there is a price impact we need to look at the price path after the event. The driftless price path after an ELC-long breach suggests that the price impact from selling the underlying upon a stoploss event is negligible. At first this pattern is reassuring for ELC-long investors. However, our finding that after the event the price closely tracks $K$ is inconsistent with the observed average residual value of $0.21 \%$ for intraday triggers.

The stockprice pattern around ELC-short terminations strokes better with the observed average residual value shortfall. The clearly discernable hump that follows ELC-short knockouts is approximately $0.20 \%$ high.

The difference between the price patterns may be due to the fact that ELC-shorts have larger open interests, or that issuers unwind short positions more aggressively. ${ }^{30}$ In any case the economic significance of the observed price impact is low. Moreover, the posttrigger price path suggests that there are no large scale arbitrage activities associated with stoploss events.

The turnover pattern also offers clues regarding the efficiency of the ELC-unwind procedure. We clearly distinguish an increased turnover around the stoploss event. The turnover naturally peaks during the trigger second, because it is the event-second which by definition sees trade in all stocks. The increased turnover before the event may be explained by the larger average price movements: When the average price moves more, there is likely to be more trade. After the trigger however there prices remain flat. We attribute the increased turnover during the half hour following the event (and during the hump, in panel B) to the unwinding of the ELC. The turnover pattern in panels $C$ and $D$ further suggest that some front running may occur, especially for ELC-shorts. It is not inconceivable that issuers simultaneously unwind and knock out the instruments. It is a

\footnotetext{
${ }^{30}$ We checked the robustness of our findings by dividing the events into subsamples. For three subsamples made on calendar months and for a two subsamples based on the alphabetic order of underlying, the post event price pattern remains flat for ELC-long breaches, and hump-sized for ELC-short breaches.
} 
frequently heard accusation, which is difficult to monitor. In any case, the post-event price path suggests that the economic loss to front-running is negligible.

\section{Summary and Conclusions}

In this paper we have described a novel and increasingly popular structured product, the Endless Leverage Certificate, which essentially is a long or short position with an attached margin account and a contractual stoploss procedure.

ELCs have several desirable properties. First, the lower bound value of the product, the intrinsic value, is easy to ascertain and compare with market prices. Because the value of the option component is very small, investors are easily reassured about the fairness of the pricing, as they do not need to worry about implied volatilities or Greeks. Indeed, for ELC-longs we find an average premium vis-à-vis the lower bound value that is merely $0.14 \%$ of the underlying value that it claims.

Second, bid-ask spreads in the secondary market are narrow. This implies that for financially constrained investors and short horizon traders, ELCs may well offer higher expected returns than investing in the underlying directly. For constrained investors this is the case because margin fees and interest rates are likely to be significantly higher than the credit spread charged on ELCs' financing levels. But even unconstrained investors may find it advantageous to buy an ELC instead of the underlying security. This is because due to its lever, the market value of an ELC is a fraction of the value of the underlying that it claims. If brokerage fees increase in transaction value, the cost of a round trip in an ELC is likely to be lower than a round trip in the underlying. The transaction cost advantage may well outweigh the slightly higher leverage adjusted bid ask spreads in the ELC market, and, depending on the investment horizon, the lower equilibrium expected returns.

ELCs also have desirable 'behavioral' properties. First, the interests of the issuer and the investor are aligned: If an investor buys an ELC from an issuer, both parties hope that the security increases in value. If the underlying moves the in the right direction, the issuer holds a virtually riskfree bond on which it earns a significant credit spread, whereas the ELC-holder benefits via the equity component. If investors are overconfident upon a 
lucky outcome, they may hold on to the ELC longer than is optimal, which also benefits the issuer. Second, the limited liability feature of ELCs is attractive to investors with loss aversion. Clearly, a portfolio of ELCs can wreak less havoc than a portfolio of equally levered positions with a shared margin account. ${ }^{31}$

We derive a pricing algorithm that takes into account the limited liability option that accrues to the ELC-holder. In a world without transaction costs, this option justifies the credit spread on the financing levels. Because credit spreads are fixed over the term of the product, there is an optimal exercise level for the underlying. If the underlying breaches this level holders should exercise because the credit spread is no longer commensurate with the value of the limited liability option. We use Monte Carlo simulation to value a typical ELC on an average DAX stock and find its value to be less than $0.10 \%$ higher than the intrinsic value (less than $0.30 \%$ higher for ELC-shorts). Our analysis also reveals that a typical ELC-long (-short) written on an average DAX-stock should be exercised when the lever falls below 16.6 (10.8), and that the expected lifespan in a frictionless world with rational investors is less than a week.

The Achilles heel of ELCs is the unwind procedure. Upon breach of a stoploss, issuers are contractually bound to exert "best efforts" to liquidate the hedging position and return the proceeds to ELC holders. However, the fairness of the unwind procedure is difficult to monitor. Issuers go to great length to improve transparency, among others by posting residual values and knockout dates and times on their websites. We study a large sample of residual values and find that upon stoploss selling, issuers passed on $99.73 \%$ of the stoploss trigger to the investors, and that upon stoploss buying, issuers paid $100.28 \%$ of the stoploss trigger to cover the shortposition. These shortfalls can be explained by discontinuous trading and by a price impact. An intraday event study does not reveal strong evidence for front-running of trigger events, and suggests that in any case, the economic cost of the price impact of the unwind procedure is low.

\footnotetext{
${ }^{31}$ Of course, margin investors can submit stoploss orders for each position. Still, the limited liability feature of ELCs and the stoploss commitment is likely to be attractive to speculators.
} 


\section{References}

Amihud, Y., and H. Mendelson. "Liquidity, Maturity, and the Yield on U.S. Treasury Securities.” Journal of Finance, 46 (1991), 479-486.

Baubonis, C.; G.L. Gastineau; and D. Purcell “The Banker's Guide to Equity-linked Certificates of Deposit." Journal of Derivatives, 1 (1993), 87-95.

Biais, B., and P. Hillion. "Insider and Liquidity Trading in Stock and Option Markets." Review of Financial Studies, 7 (1994), 743-780.

Breuer, W., and A. Perst. "Retail Banking and Behavioural Financial Engineering: the Case of Structured Products." Unpublished working paper (2006), Aachen University of Technology.

Brown, C., and K. Davis. "Dividend Protection at a Price.", Journal of derivatives, 12 (2005), 62-68.

Burth, S.; T. Kraus; and H. Wohlwend, H. "The Pricing of Structured Products in the Swiss Market.” Journal of Derivatives, 9 (2001), 30-40.

Chan, H.W.H., and S.M. Pinder. "The Value of Liquidity: Evidence from the Derivatives Market." Pacific-Basin Finance Journal, 8 (2000), 483-503.

Chan, K.; P. Chung; and H. Johnson. "The Intraday Behavior of Bid-Ask spreads for NYSE Stocks and CBOE Options." Journal of Financial and Quantitative Analysis, 30 (1995), 329-346.

Chen, A.H., and J.W. Kensinger. "An Analysis of Market-index Certificates of Deposit." Journal of Financial Services Research, 4 (1990), 93-110.

Chen, K.C., and R.S. Sears. "Pricing the SPIN." Financial Management, 19 (1990), 36-47.

Entrop O.; H. Scholz; and M. Wilkens. "The Price Setting Behavior of Banks: an Analysis of Open-end Leverage Certificates on the German Market." Unpublished working paper (2007), Catholic University Ingolstadt.

Grünbichler, A., and H. Wohlwend. "The Valuation of Structured Products: Empirical Findings for the Swiss Market", Financial markets and portfolio management, 19 (2005), 361-380.

McConnell, J., and E. Schwartz. "LYON Taming.” Journal of Finance, 43 (1986), 561 -576.

Muck, M. "Pricing Turbo Certificates in the Presence of Stochastic Jumps, Interest Rates and Volatility, Unpublished working paper (2006), University of Mannheim.

Peavy, J.W. "Returns on Initial Public Offerings of Closed-end Funds." Review of Financial Studies, 3 (1990), 695-708.

Scholz, H.; R. Baule; and M. Wilkens. "Innovative Turbo-Zertifikate am deutschen Kapitalmarkt - Preisstellung, Bewertung, Hedging und Gewinnpotential”, Unpublished working paper (2004), Catholic University Ingolstadt.

Stoimenov, P.A., and S. Wilkens. "Are Structured Products Fairly Priced? An Analysis of the German Market for Equity-linked Instruments.” Journal of Banking and Finance, 29 (2005), 2971-2993. 
ter Horst, J., and C. Veldt, "Behavioral Preferences for Individual Securities: The Case for Call Warrants and Call Options.” Unpublished Working Paper (2004), Tilburg University.

Wasserfallen, W., and C. Schenk. "Portfolio Insurance for the Small Investor in Switzerland." Journal of Derivatives, 3, (1996), 37-43.

Weiss, K. "The Post-offering Price Performance of Closed End Funds." Financial Management, 18 (1989), 57-67.

Wilkens, S.; C. Erner; and K. Roeder. "The Pricing of Structured Products in Germany." Journal of Derivatives, 11 (2003), 55-69. 


\section{Appendix: Monte Carlo Simulation}

We estimate the option component of a typical ELC in two stages. First we look for the optimal exercise level $E^{*}$. Then we estimate the value of the option component, $D$ - $L^{\prime \prime}\left(S^{\prime \prime} \mid D, K, E^{*}\right)$. To find $E^{*}$, we set $D_{t}=€ 100$ and $K_{t} \in\{€ 105, € 103.50\}$. We try a high $E_{t}$ and set $S_{t}=E_{t}$. We then simulate 100,000 runs for the underlying:

1) set $i=1$

2) Let the critical levels increase: Set $D_{t+i}=D_{t} e^{i \cdot r_{E L C}} ; K_{t+i}=K_{t} e^{i \cdot r_{E L C}} ; E_{t+i}=E_{t} e^{i \cdot r_{E L C}}$

3) Randomly pick, with replacement, an overnight return from the pooled overnight returns of the DAX-stocks during last 15 years. With this we compute the hypothetical $S_{t+i}^{\prime}$. If $S_{t+i}^{\prime}<K_{t+i}$, the present value of the loan payoff is $e^{-i r} \min \left(D_{t+i}, S_{t+i}^{\prime}\right)$. Go to 7).

4) Randomly pick, with replacement, an open-low return, to compute $S_{t+i}^{\text {low }}$. If $S_{t+i}^{\text {low }}<K_{t+i}$, the discounted loan-payoff is $e^{-i r} D_{t+i}$, Go to 7).

5) Apply the low-close return that occurred on the same day for the same stock as the open-low return picked in 4). Use this return to compute a hypothetical $S_{t+i}^{\prime \prime}$. If $S_{t+i}^{\prime \prime}>E_{t+i}$, the discounted loan payoff is $e^{-i r} D_{t+i}$, go to 7)

6) Set $i$ to $i+1$, go to 2 )

7) Record the loan payoff, the lifespan of the ELC, the kind of termination (overnightstoploss, intraday-stoploss, or exercise), go to 1) to simulate another run.

After 100,000 'runs', we record the average discounted loan payoff. If it is higher than $€ 100$, the assumed $E_{t}$ is too high, and we repeat the simulation with a lower $E_{t}$ until we find the $E_{t}$ for which the average discounted loan payoff is just $€ 100$. We denote this $E_{t}$ the optimal exercise level $E_{t}^{*}$.

To find the value of the ELC option component as a function of the underlying, we run the same simulations, but with $E_{t}=E_{t}^{*}$, and let $S_{t}$ vary between $K_{t}$ and $E_{t}^{*}$. We also record the default probability, average life, and the recovery rates. 
Remark: we assume 250 days per year, and no weekends nor holidays. The overnight interest rate $r$ was set at $0.016 \%$ (4\% annualized), approximately the historic average overnight rate. Using a different $r$ gives virtually the same results. The option component is mainly driven by the tails of the intraday and nighttime distributions. 
Figure 1: Payoff diagrams for Endless Leverage Certificates

The picture on the left gives the payoff and the value of an ELC-long, as a function of the value of the underlying, $S$. The diagram on the right depicts the same relationships for an ELC-short. Notice that we exaggerate the wedge between the value and payoff lines. For most ELCs, the stoploss level $K$ is sufficiently far from financing level $D$ to make the option component inappreciably small.
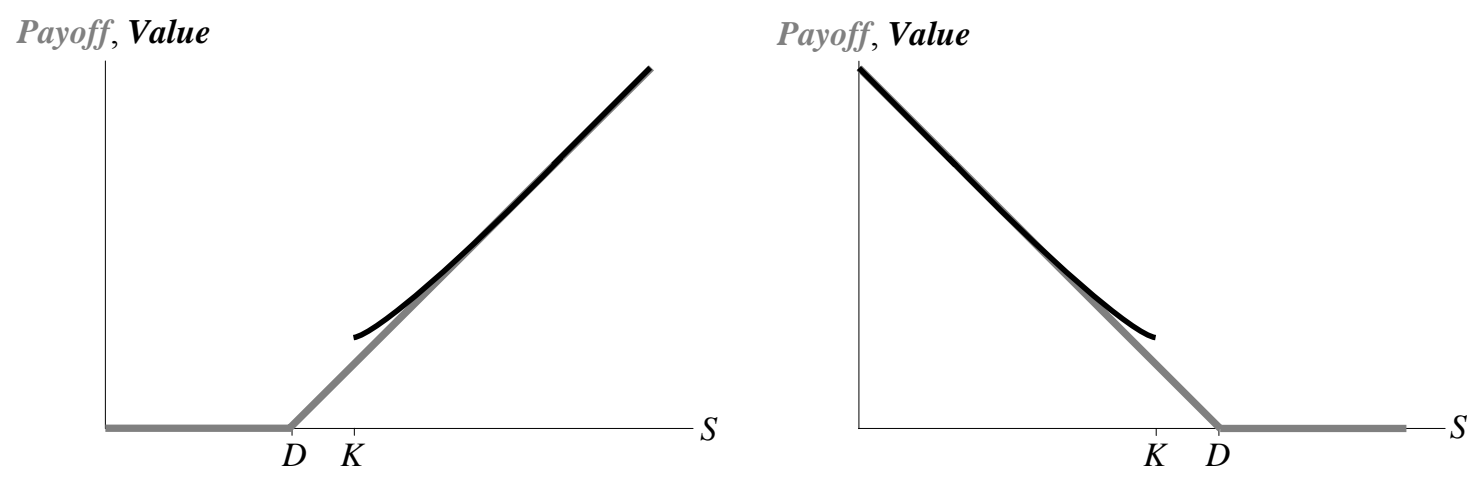
Figure 2: Overview of the market for Endless Leverage Certificates.

Panel A gives the number of ELC-contracts that were outstanding, issued and terminated, in Germany and the Netherlands, in 2006, by month. Panel B shows the approximate market shares, during the last quarter of 2006, of all active issuers by trading turnover of their ELCs. Panel C gives a decomposition of the ELC market in different types of underlying, both in trading turnover and in number of contracts. Source: websites of ABN-AMRO, Commerzbank, DDI (Deutsches Derivate Institut)

Panel A: ELCs outstanding, issued and terminated, by month

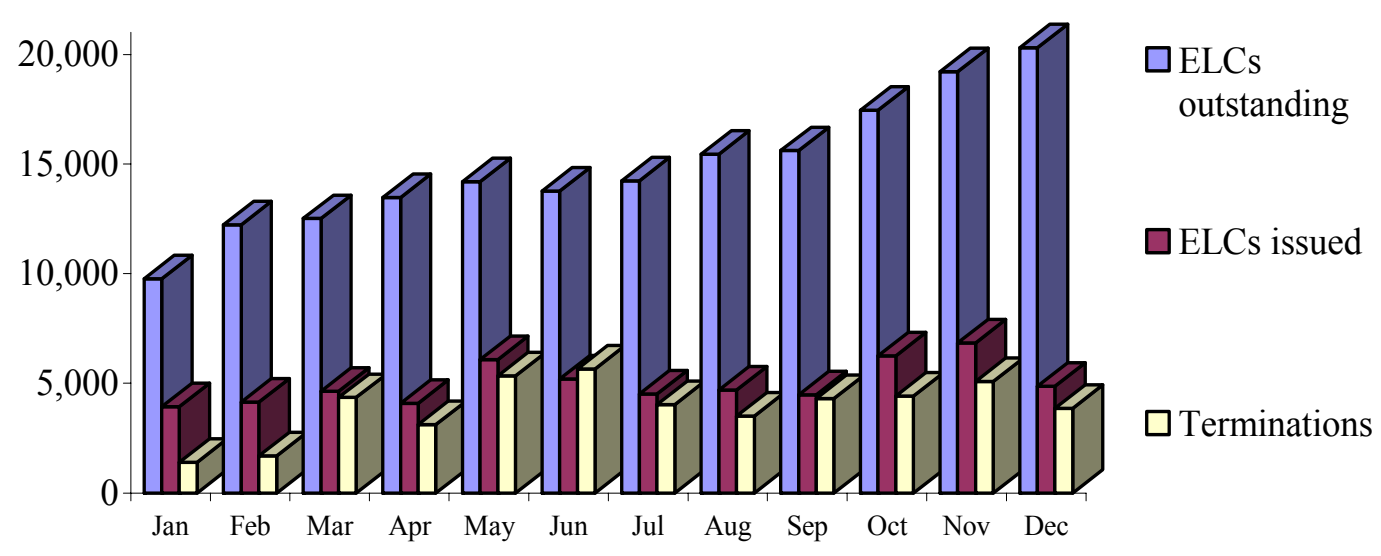

Panel B: Issuer market shares by trading turnover
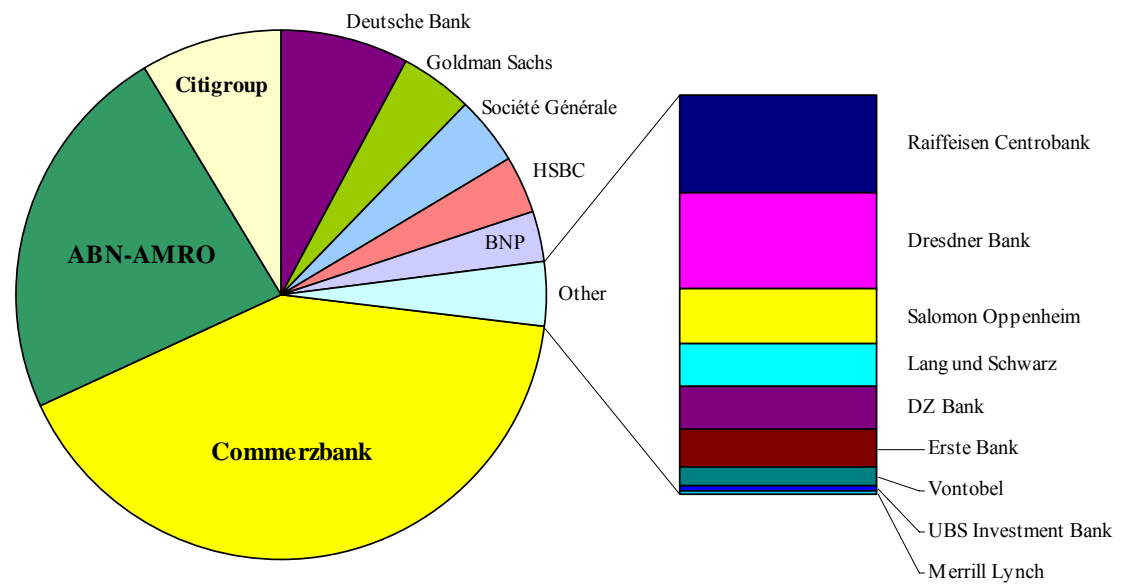

Panel C: Market shares by types of underlying

C1: By contracts outstanding

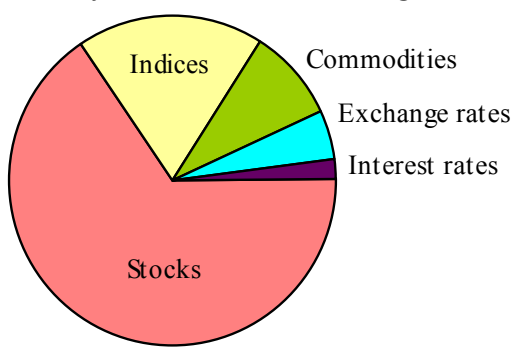

$\mathrm{C} 2$ : By trading turnover

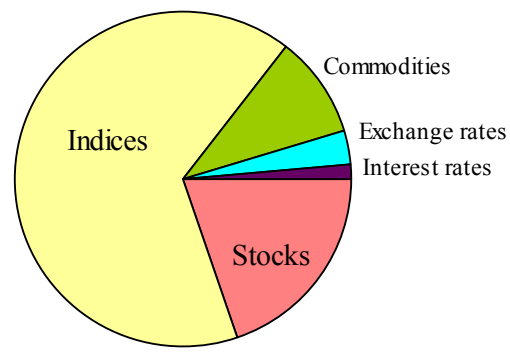




\section{Table 1: Overview of stock-ELCs by issuer}

This table gives the main characteristics of the ELCs of the eight largest issuers in Germany and the Netherlands. The information is accurate on January 2007. In the interest rate row, EONIA stands for Euro OverNight Index Average, and Euribor for the one-month Euro Interbank Offered Rate. Both are average effective interest rates on euro-denominated loans as quoted a large bank panel. In the Residual Value Reporting row $R V$ stands for Residual Value, $D$ for the financing level, and $K$ for the stoploss level.

\begin{tabular}{|c|c|c|c|c|c|c|c|c|}
\hline & Bank A & Bank B & Bank C & Bank D & Bank E & Bank F & Bank G & Bank H \\
\hline Name in Germany & Mini Futures & Stop Loss Turbos & Unlimited Turbos & WAVE XXL & Mini Futures & Mini Futures & Endless Turbos & Open End Turbos \\
\hline Name in Netherlands & Turbos & Unlimited Speeders & Speeders & & & & & \\
\hline Prospectus & English / German & English / German & English / German & German & German & German & German & German \\
\hline Interest on longs & Euribor $+150 \mathrm{BP}$ & Euribor $+200 \mathrm{BP}$ & Euribor $+140 \mathrm{BP}$ & $\mathrm{EONIA}+325 \mathrm{BP}$ & Euribor $+200 \mathrm{BP}$ & EONIA + 150BP & Euribor $+200 \mathrm{BP}$ & Euribor $+250 \mathrm{BP}$ \\
\hline Interest on shorts & Euribor - 150BP & Euribor - 200BP & $0 \%$ & EONIA - 325BP & Euribor - 200BP & EONIA - $150 \mathrm{BP}$ & Euribor - 200BP & Euribor - 250BP \\
\hline Stop loss reset & $\begin{array}{l}\text { monthly, first } \\
\text { businessday } \\
\text { after 15th }\end{array}$ & $\begin{array}{l}\text { monthly, first } \\
\text { businessday of } \\
\text { each month }\end{array}$ & $\begin{array}{l}\text { monthly, first } \\
\text { businessday of } \\
\text { each month }\end{array}$ & $\begin{array}{l}\text { monthly, first } \\
\text { businessday of } \\
\text { each month }\end{array}$ & $\begin{array}{l}\text { monthly, first } \\
\text { businessday of } \\
\text { each month }\end{array}$ & daily & daily & $\begin{array}{l}\text { monthly, } 15 \text { th } \\
\text { calender day of the } \\
\text { month }\end{array}$ \\
\hline Residual value reporting & $R V$, date, $D, K$ & $R V$, date, $K$ & $R V$, date, $K$ & $R V$, date, $D, K$ & $R V$, date & $R V$, date, $D, K$ & $R V$, date, $D, K$ & $R V$, date, $K$ \\
\hline Residual Value & $\begin{array}{l}\text { Obtained from } \\
\text { "unwinding of the } \\
\text { hedging position } \\
\text { on a best efforts } \\
\text { basis". At least } \\
\text { "minimum value } \\
\text { during stoploss day } \\
\text { and next day if } \\
\text { stoploss in final } \\
\text { three hours of } \\
\text { trading" }\end{array}$ & $\begin{array}{l}\text { Obtained from the } \\
\text { "dissolution of } \\
\text { Hedge Position". } \\
\text { "Issuer will disolve } \\
\text { Hedge Position } \\
\text { within } 60 \text { minutes } \\
\text { after Knock-Out." }\end{array}$ & $\begin{array}{l}\text { "determined by the } \\
\text { calculation agent in } \\
\text { its own reasonable } \\
\text { discretion as the } \\
\text { fair market value" }\end{array}$ & $\begin{array}{l}\text { "fair market value } \\
\text { determined at the } \\
\text { issuer's discretion } \\
\text { based on the } \\
\text { dissolution of the } \\
\text { hedging position } \\
\text { within the three } \\
\text { hours following the } \\
\text { stop-loss event" }\end{array}$ & $\begin{array}{l}\text { "based on the } \\
\text { knock-out market } \\
\text { value of the } \\
\text { underlying, which } \\
\text { is at least the for } \\
\text { the investor most } \\
\text { unfavourable quote } \\
\text { within the three } \\
\text { hours following the } \\
\text { knock-out event" }\end{array}$ & $\begin{array}{l}\text { "The hedging } \\
\text { position will be } \\
\text { dissolved within } 60 \\
\text { minutes [...] } \\
\text { investors will be } \\
\text { paid the difference } \\
\text { between the } \\
\text { realized value of } \\
\text { the underlying and } \\
\text { the financing level" }\end{array}$ & $\begin{array}{l}\text { "depending on the } \\
\text { dissolution of the } \\
\text { hedging position, } \\
\text { the issuer will try } \\
\text { to pay a fair market } \\
\text { value per } \\
\text { certificate" }\end{array}$ & $\begin{array}{l}\text { "At least the } \\
\text { difference between } \\
\text { value of the } \\
\text { underlying as } \\
\text { determined by the } \\
\text { issuer within three } \\
\text { hours after the stop. } \\
\text { loss event and the } \\
\text { financing level" }\end{array}$ \\
\hline Exercisable & $\begin{array}{l}\text { yearly, last trading } \\
\text { day of March }\end{array}$ & $\begin{array}{l}\text { monthly, last day } \\
\text { of month, upon } \\
\text { written request }\end{array}$ & $\begin{array}{l}\text { monthly, first day } \\
\text { of month, } 28 \\
\text { days notice }\end{array}$ & $\begin{array}{c}\text { yearly, first } \\
\text { business day after } \\
\text { August } 7\end{array}$ & daily & $\begin{array}{l}\text { monthly, first } \\
\text { business day of the } \\
\text { month }\end{array}$ & daily & daily \\
\hline Ratios & Mostly 1:10 & Mostly 1:10 & Mostly 1:10 & Mostly 1:10 & $\begin{array}{l}\text { Mixed between } \\
1: 1,1: 10,1: 100\end{array}$ & Mostly 1:10 & Mostly 1:10 & $\begin{array}{c}\text { Mostly } 1: 1 \text { and } \\
1: 10\end{array}$ \\
\hline
\end{tabular}




\section{Table 2: Overview of stock-ELCs in Germany}

This table gives further ELC characteristics for the eight largest issuers in the German market. The stock ELCs include ELCs written on nonGerman stocks. Credit spreads are given in basis points. The lever is defined as $S /|S-D|$ and the stoploss premium as $|K-D| / D$. The characteristics were computed for all stock-ELCs outstanding on January $16^{\text {th }} 2007$. Average bid-ask spreads are based on five snapshots in January 2007 . We sourced the data from Internet broker www.cortalconsors.com, and DDI.

\begin{tabular}{|c|c|c|c|c|c|c|c|c|c|}
\hline \multirow{2}{*}{\multicolumn{2}{|c|}{ Total ELCs }} & Bank A & Bank B & Bank $C$ & Bank D & Bank $E$ & Bank $F$ & Bank $G$ & Bank $H$ \\
\hline & & 2,106 & 676 & 2,251 & 889 & 1,451 & 813 & 525 & 1,518 \\
\hline \multicolumn{2}{|c|}{ Stock ELCs } & 1,193 & 526 & 1,637 & 666 & 686 & 723 & 327 & 991 \\
\hline \multicolumn{2}{|c|}{ Nr. stocks covered } & 78 & 47 & 83 & 41 & 41 & 37 & 34 & 43 \\
\hline \multicolumn{2}{|c|}{ Longs } & 1,318 & 423 & 1,733 & 647 & 810 & 599 & 343 & 1,270 \\
\hline \multicolumn{2}{|c|}{ Shorts } & 788 & 253 & 518 & 242 & 641 & 214 & 182 & 248 \\
\hline \multirow{5}{*}{$\begin{array}{l}\infty \\
\text { b } \\
\tilde{0} \\
\stackrel{1}{+}\end{array}$} & credit spread (BP) & 150 & 200 & 140 & 300 & 200 & 150 & 200 & 250 \\
\hline & average lever & 3.36 & 6.18 & 3.98 & 4.08 & 6.36 & 4.08 & 5.63 & 3.07 \\
\hline & at issue & 6.21 & 11.21 & 9.33 & 7.25 & 7.03 & 8.86 & 8.38 & 4.91 \\
\hline & av. stoploss premium & $9.1 \%$ & $3.5 \%$ & $5.5 \%$ & $6.4 \%$ & $7.6 \%$ & $7.9 \%$ & $4.8 \%$ & $6.6 \%$ \\
\hline & average age (days) & 339 & 126 & 384 & 225 & 163 & 349 & 151 & 541 \\
\hline \multirow{5}{*}{$\frac{n}{\tilde{0}}$} & credit spread (BP) & 150 & 200 & 310 & 300 & 200 & 150 & 200 & 250 \\
\hline & average lever & 4.12 & 7.80 & 5.41 & 6.45 & 7.15 & 7.18 & 6.97 & 4.60 \\
\hline & at issue & 4.42 & 6.77 & 5.92 & 7.80 & 6.52 & 7.52 & 6.55 & 4.30 \\
\hline & av. stoploss premium & $9.80 \%$ & $3.97 \%$ & $5.62 \%$ & $6.56 \%$ & $7.77 \%$ & $6.49 \%$ & $5.30 \%$ & $6.22 \%$ \\
\hline & average age (days) & 241 & 147 & 253 & 63 & 153 & 164 & 112 & 398 \\
\hline \multicolumn{2}{|c|}{$\begin{array}{l}\text { average quoted bid/ask } \\
\text { spread ( } \% \text { of midprice) }\end{array}$} & $1.10 \%$ & $1.22 \%$ & $0.84 \%$ & $1.29 \%$ & $1.58 \%$ & $1.21 \%$ & $1.44 \%$ & $1.03 \%$ \\
\hline \multicolumn{2}{|c|}{$\begin{array}{l}\text { average leverage-adjusted } \\
\text { spread }(\%)\end{array}$} & $0.30 \%$ & $0.18 \%$ & $0.20 \%$ & $0.27 \%$ & $0.24 \%$ & $0.25 \%$ & $0.24 \%$ & $0.31 \%$ \\
\hline \multicolumn{2}{|c|}{$\begin{array}{l}\text { average monthly trading } \\
\text { turnover per ELC }(€)\end{array}$} & 322,600 & 415,577 & 623,640 & 315,604 & 216,849 & 278,698 & 198,765 & 89,760 \\
\hline
\end{tabular}


Table 3: Bid-Ask Spreads of Stocks, ELCs, and Options

We take 20 intraday snapshots of bid and ask quotes for 30 German DAX stocks and 25 Dutch AEX, and five snapshots for all ELCs and options written on them. The sampling snapshots were taken on five different days in January 2007. The ratio adjusted $€$-spread for an ELC is the gross $€$-spread multiplied by the ratio. The ratio and delta adjusted $€$-spreads for the covered warrants and options are computed by multiplying the gross $€$-spread with the option's ratio (unity for all Euronext options) and the option's delta, which is computed with the Black-Scholes formula. In the bottom panel we list the proportional spreads. The gross spreads are the spreads (bid minus ask) divided by the midprice of the derivative. The leverage adjusted spreads are the gross spreads divided by the lever. The lever for an ELC is defined as $S /|S-D|$. The lever for an option is defined as the hedge-ratio multiplied by the value of the underlying, divided by the midprice of the security ( $\delta S / C$ for calls, $\delta S / P$ for puts).

\begin{tabular}{|c|c|c|c|c|c|c|}
\hline & & & & y: Xetra- & $\mathrm{X}$ stocks & \\
\hline & & 30 stocks & & $\mathrm{LCs}$ & 18,003 & red warrants \\
\hline & & & gross & $\begin{array}{c}\text { ratio } \\
\text { adjusted }\end{array}$ & gross & $\begin{array}{c}\text { ratio and delta } \\
\text { adjusted }\end{array}$ \\
\hline & average & 6.2 & 4.9 & 17.3 & 2.1 & 25.7 \\
\hline & $\min$ & 1.0 & 1.0 & 1.0 & 0.2 & 1.0 \\
\hline की $\widehat{0}$ & $25 \%$-percentile & 2.0 & 1.0 & 6.0 & 1.0 & 12.1 \\
\hline 芩 & median & 3.0 & 2.0 & 10.0 & 1.0 & 17.2 \\
\hline 象 & $75 \%$-percentile & 5.0 & 5.0 & 20.0 & 2.0 & 25.4 \\
\hline & $\max$ & 150.0 & 150.0 & 200.0 & 22.0 & 462.9 \\
\hline & stdev & 16.4 & 10.9 & 25.1 & 2.7 & 45.9 \\
\hline & & 30 stocks & & $\mathrm{LCs}$ & 18,003 & red warrants \\
\hline & & & gross & $\begin{array}{l}\text { leverage } \\
\text { adjusted }\end{array}$ & gross & $\begin{array}{c}\text { leverage } \\
\text { adjusted }\end{array}$ \\
\hline & average & 6.4 & 97.7 & 24.3 & 655.3 & 46.4 \\
\hline$\overparen{\Xi}$ & $\min$ & 1.3 & 2.6 & 1.1 & 7.9 & 2.1 \\
\hline की है & $25 \%$-percentile & 3.2 & 36.6 & 12.4 & 109.3 & 18.5 \\
\hline$\stackrel{0}{ \pm} \cdot \frac{n}{n}$ & median & 4.7 & 62.4 & 17.8 & 235.3 & 29.5 \\
\hline$\frac{\pi}{0}$ & $75 \%$-percentile & 6.8 & 115.1 & 26.2 & 606.1 & 50.8 \\
\hline & $\max$ & 37.9 & $1,639.3$ & 292.5 & $14,782.6$ & $4,607.6$ \\
\hline & stdev & 6.0 & 112.5 & 24.2 & $1,244.1$ & 106.4 \\
\hline
\end{tabular}

\begin{tabular}{|c|c|c|c|c|}
\hline \multicolumn{5}{|c|}{ Netherlands: AEX-stocks } \\
\hline 25 stocks & \multicolumn{2}{|c|}{444 ELCs } & \multicolumn{2}{|c|}{6,141 Euronext options } \\
\hline & gross & $\begin{array}{c}\text { ratio } \\
\text { adjusted }\end{array}$ & gross & $\begin{array}{c}\text { delta } \\
\text { adjusted }\end{array}$ \\
\hline 2.4 & 6.7 & 8.5 & 11.5 & 18.4 \\
\hline 1.0 & 1.0 & 1.0 & 5.0 & 5.0 \\
\hline 1.0 & 2.0 & 6.0 & 5.0 & 10.0 \\
\hline 1.0 & 6.0 & 8.0 & 10.0 & 13.1 \\
\hline 3.0 & 10.0 & 10.0 & 15.0 & 21.0 \\
\hline 13.0 & 30.0 & 30.0 & 45.0 & 291.5 \\
\hline 2.6 & 5.9 & 4.5 & 6.8 & 17.2 \\
\hline \multirow[t]{2}{*}{25 stocks } & \multicolumn{2}{|c|}{444 ELCs } & \multicolumn{2}{|c|}{6,141 Euronext options } \\
\hline & gross & $\begin{array}{l}\text { leverage } \\
\text { adjusted }\end{array}$ & gross & $\begin{array}{l}\text { leverage } \\
\text { adjusted }\end{array}$ \\
\hline 8.7 & 143.5 & 35.0 & 644.5 & 97.8 \\
\hline 1.7 & 25.9 & 2.9 & 26.4 & 2.6 \\
\hline 3.4 & 75.6 & 21.2 & 162.7 & 38.9 \\
\hline 7.4 & 113.5 & 29.7 & 286.4 & 70.2 \\
\hline 10.5 & 181.8 & 40.4 & 555.6 & 114.0 \\
\hline 30.4 & 800.0 & 196.2 & $10,000.0$ & 827.2 \\
\hline 6.8 & 103.6 & 22.1 & $1,198.2$ & 95.0 \\
\hline
\end{tabular}




\section{Table 4: Determinants of Leverage Adjusted Bid-Ask Spreads}

This table gives the results of a regression analysis in which the dependent variable is the leverage-adjusted bid-ask spread, which is the spread for the ELC, expressed as a proportion of the value of the underlying position. The data come from five quote snapshots on different days in January 2007 of 2,572 ELC-longs and 849 ELC-shorts written on the 30 Xetra-DAX stocks, by the ten largest issuers. The lever is calculated as $S /|S-D|$ and the stoploss premium as $|K-D| / D$. The volatility of the underlying is the annualized standard deviation of daily returns computed over up to 15 years worth of historical data. White heteroscedasticity consistent standard errors are given in parentheses. ***, **, and * indicate a significance levels of $1 \%, 5 \%$, and $10 \%$ respectively.

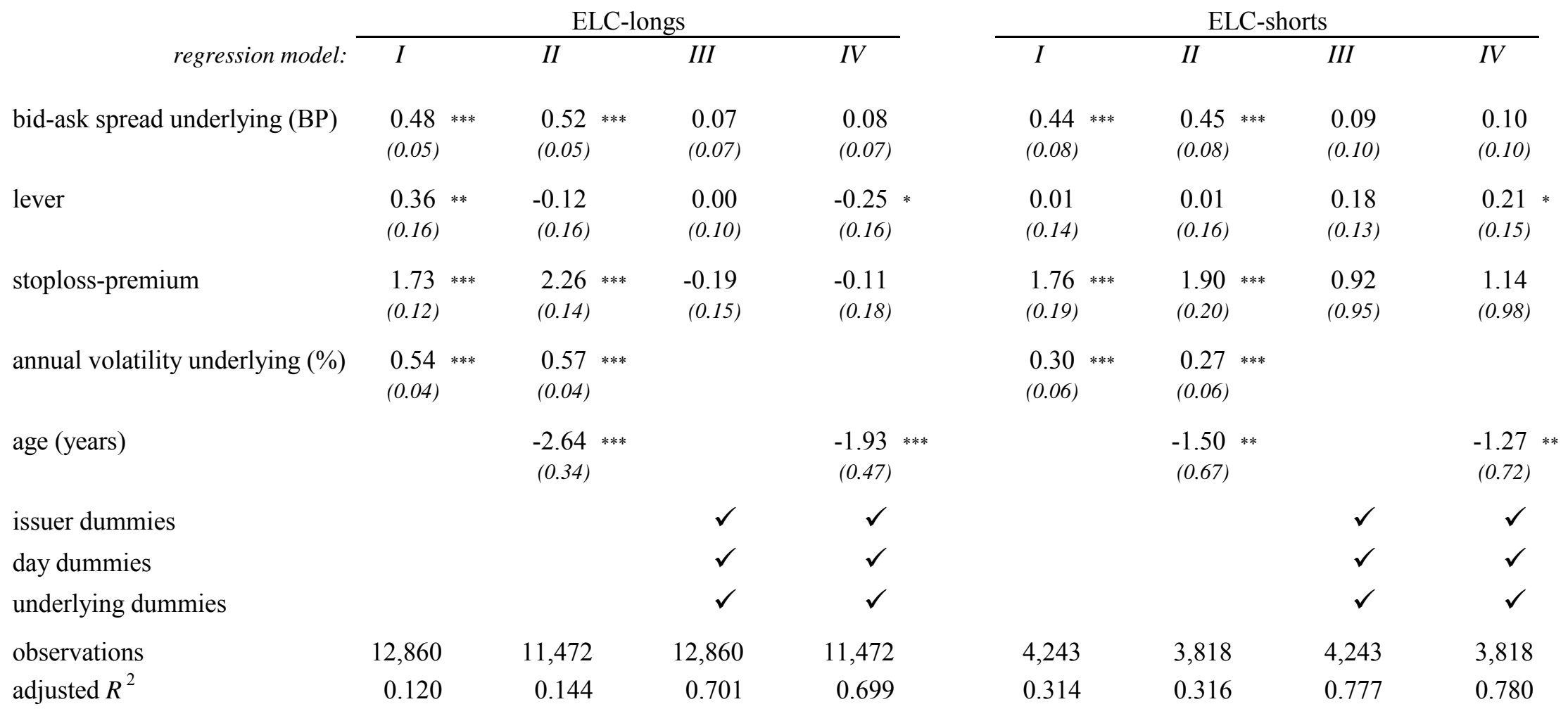




\section{Table 5: ELC overpricing vis-à-vis Intrinsic Values}

We take five intraday snapshots of bid and ask quotes for 5,129 ELCs written on German DAX stocks and 444 ELCs written on Dutch AEX stocks and match them with the contemporaneous bid and ask quotes of the underlying securities. For each ELC-snapshot, we compute the absolute overpricing as $A O P \equiv 1 / 2\left(E L C_{A}+E L C_{B}\right)-\left|1 / 2\left(S_{A}+S_{B}\right)-D\right|$, the absolute relative overpricing as $A O P /\left.\right|_{1} ^{1} / 2\left(S_{A}+S_{B}\right)-D \mid$, and the overpricing relative to the underlying as $A O P /\left(1 / 2\left(S_{A}+S_{B}\right)\right)$.

Germany: 5,129 ELCs on 30 DAX stocks

\begin{tabular}{|c|c|c|c|c|c|c|}
\hline & \multicolumn{3}{|c|}{ 3,898 ELC-Longs } & \multicolumn{3}{|c|}{ 1,231 ELC-Shorts } \\
\hline & $\begin{array}{c}\text { absolute } \\
(€)\end{array}$ & $\begin{array}{c}\% \text {-age of } \\
\qquad|S-D|\end{array}$ & $\begin{array}{c}\% \text {-age of } \\
\text { underlying }\end{array}$ & $\begin{array}{c}\text { absolute } \\
(€)\end{array}$ & $\begin{array}{c}\% \text {-age of } \\
|S-D|\end{array}$ & $\begin{array}{c}\% \text {-age of } \\
\text { underlying }\end{array}$ \\
\hline average & 0.02 & 0.51 & 0.14 & 0.02 & 1.00 & 0.20 \\
\hline $1 \%$-percentile & -0.56 & -3.62 & -1.09 & -0.09 & -3.65 & -1.09 \\
\hline $25 \%$-percentile & 0.00 & -0.10 & -0.03 & 0.00 & 0.03 & -0.03 \\
\hline median & 0.01 & 0.30 & 0.10 & 0.01 & 0.58 & 0.10 \\
\hline 75\%-percentile & 0.03 & 0.89 & 0.26 & 0.03 & 1.55 & 0.26 \\
\hline $99 \%$-percentile & 0.48 & 5.70 & 1.98 & 0.22 & 9.13 & 1.98 \\
\hline standard deviation & 0.20 & 1.57 & 0.41 & 0.08 & 2.23 & 0.41 \\
\hline
\end{tabular}

Netherlands: 444 ELCs on 25 AEX-stocks

\begin{tabular}{|c|c|c|c|c|c|}
\hline \multicolumn{3}{|c|}{307 ELC-Longs } & \multicolumn{3}{|c|}{137 ELC-Shorts } \\
\hline $\begin{array}{c}\text { absolute } \\
(€)\end{array}$ & $\begin{array}{c}\% \text {-age of } \\
\quad|S-D|\end{array}$ & $\begin{array}{l}\% \text {-age of } \\
\text { underlying }\end{array}$ & $\begin{array}{c}\text { absolute } \\
(€)\end{array}$ & $\begin{array}{c}\% \text {-age of } \\
|S-D|\end{array}$ & $\begin{array}{l}\% \text {-age of } \\
\text { underlying }\end{array}$ \\
\hline 0.01 & 0.92 & 0.26 & 0.05 & 1.12 & 0.27 \\
\hline-0.19 & -2.48 & -0.65 & -0.06 & -1.21 & -0.18 \\
\hline 0.00 & 0.00 & 0.00 & 0.01 & 0.19 & 0.05 \\
\hline 0.02 & 0.57 & 0.17 & 0.02 & 0.79 & 0.21 \\
\hline 0.04 & 1.39 & 0.36 & 0.06 & 1.47 & 0.39 \\
\hline 0.10 & 7.99 & 1.42 & 0.27 & 9.65 & 1.26 \\
\hline 0.06 & 1.87 & 0.50 & 0.08 & 1.68 & 0.30 \\
\hline
\end{tabular}




\section{Table 6: Determinants of the ELC Premiums}

This table gives the results of a regression analysis in which the dependent variable is the ELC premium vis-à-vis the intrinsic value, as a proportion expressed in basispoints, of the value of the underlying. The data comes from five quote snapshots on different days in January 2007 of 2,572 ELC-longs and 849 ELC-shorts written on the 30 Xetra-DAX stocks, by the ten largest issuers. The lever is defined as $S /|S-D|$ and the stoploss premium as $|K-D| / D$. The volatility of the underlying is the annualized standard deviation of daily returns computed over up to 15 years worth of historical data. White heteroscedasticity consistent standard errors are given in parentheses. $* * *, * *$, and * indicate significance levels of $1 \%, 5 \%$, and $10 \%$ respectively.

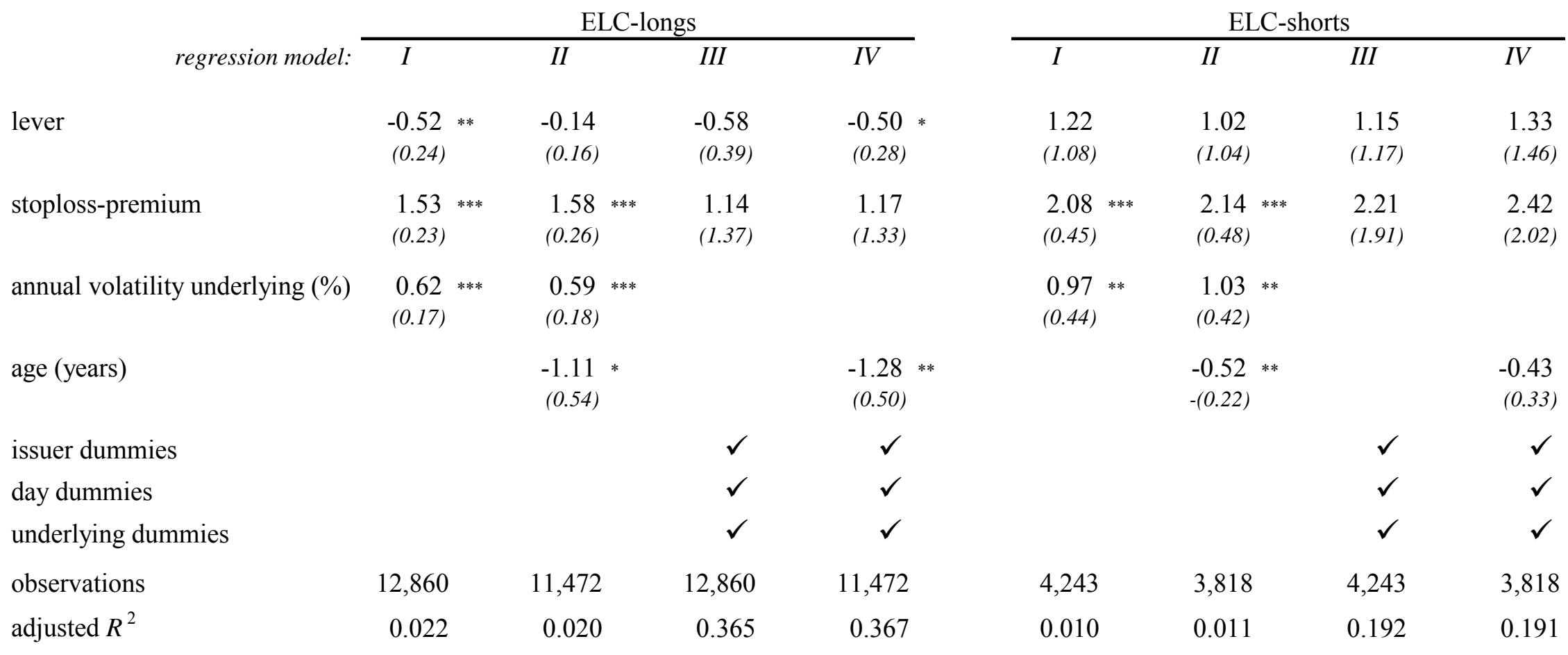


Figure 2: historical frequencies of overnight and daytime returns

The dots make up a histogram of all overnight and daytime returns for the 30 Xetra-Dax stocks over the 15 years until 11 February 2007. In total there are 97,288 returns. The Bin-width is 10 basispoints. The continuous line shows the Normal probability distribution function with the same mean and standard deviation. In the upper corners of the graph we amplified the tails of the distribution. For the overnight returns, the average was 11 basispoints, the standard deviation 119 basispoints, the skewness 1.99, and the excess kurtosis 139.87. For the daytime returns the statistics were -7 basispoints, 174 basispoints, 0.01 , and 6.30 respectively.

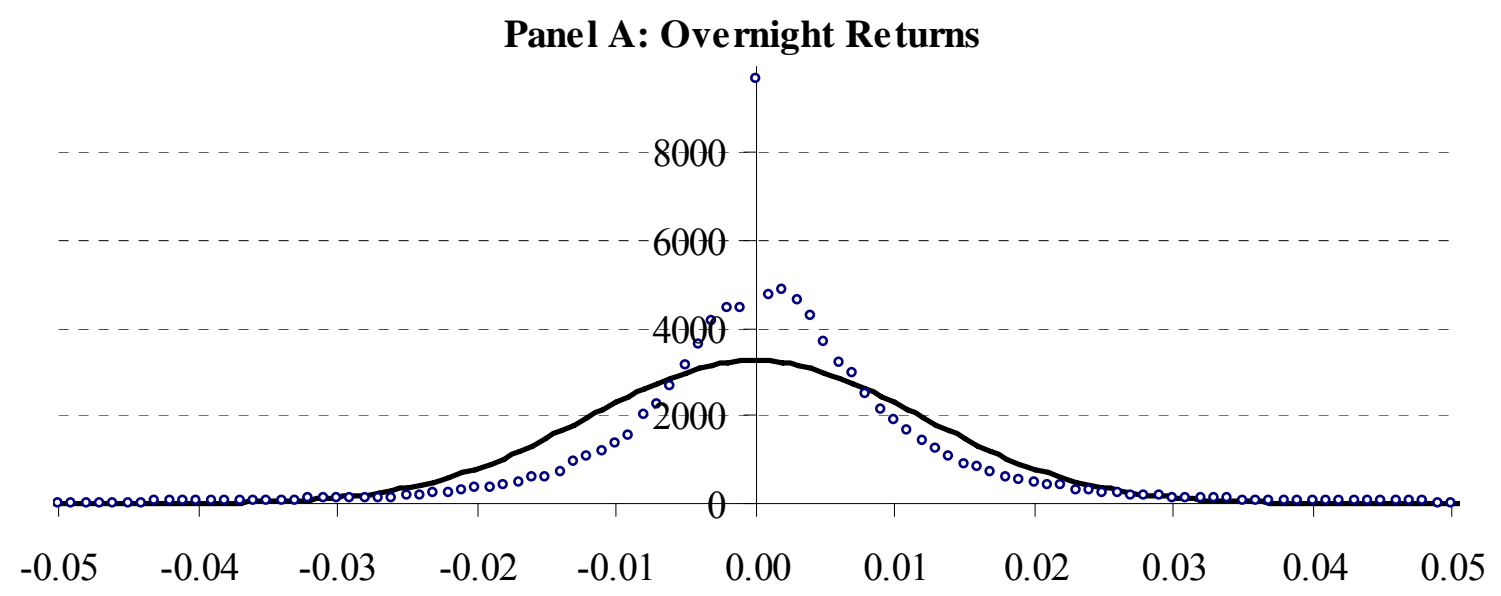

\section{Panel B: Daytime Returns}

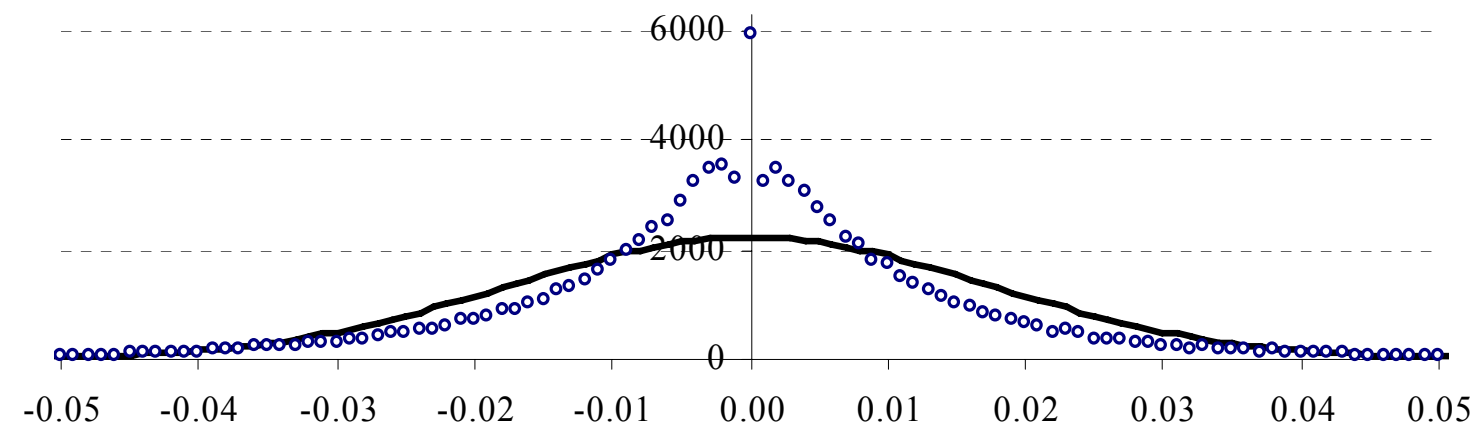




\section{Figure 3: Monte-Carlo estimated values for the ELC option value}

Using pooled historical intraday returns of all Xetra-DAX stocks, we estimate the value of the option component of ELCs. We simulate the payoff to an ELC financing level with $D=€ 100$ that is collateralized by an underlying which is be sold if it hits stoploss-level $K=€ 103.5$ or $€ 105$. Both $D$ and $K$ increase at rates that are $2 \%$ or $1.5 \%$ higher than the riskfree rate. We first use Monte Carlo simulation to search for the optimal exercise level, at which the value of the option component is zero. We find optimal exercise levels of $€ 106.40, € 108.30$, and $€ 109.30$ for ELClongs and $€ 91.50, € 89.60$ and $€ 88.20$. We then use Monte Carlo simulation to evaluate the value of the ELC for stockprices in the $[K, E]$-intervals.

Panel A: The premium vis-à-vis the intrinsic value for ELC-longs

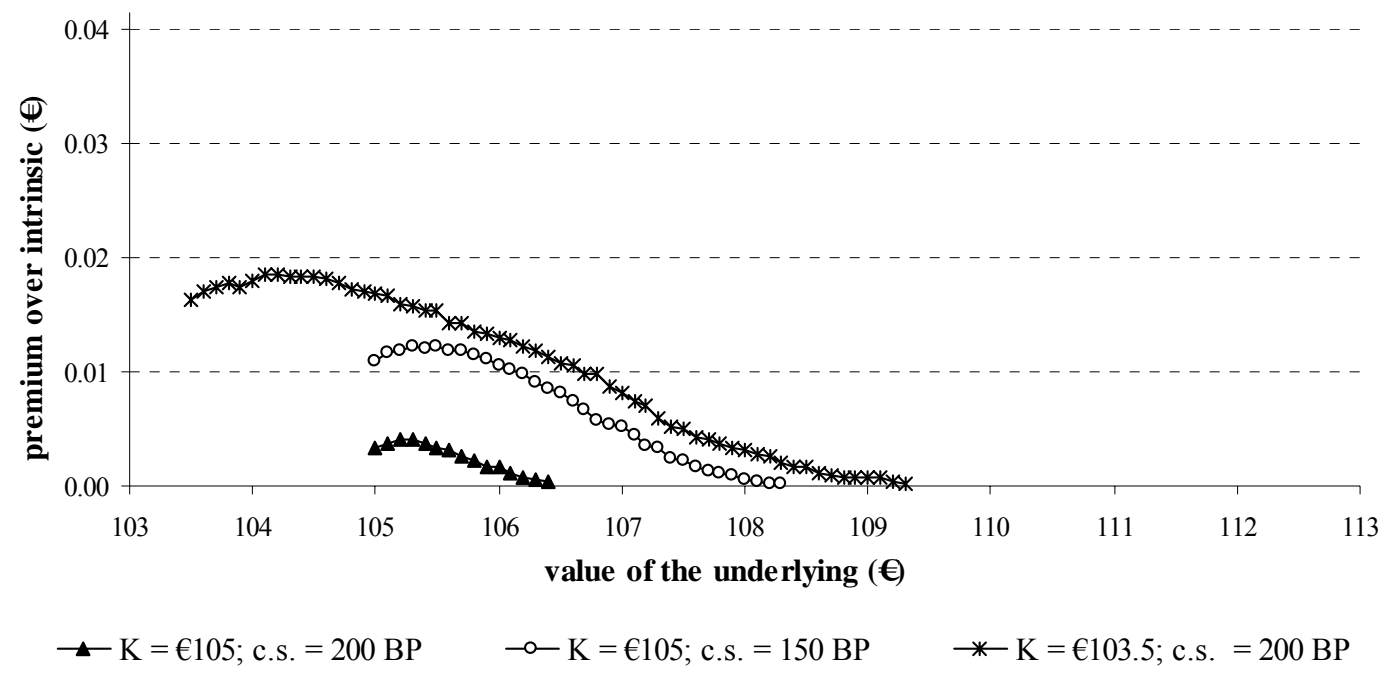

Panel B: The premium vis-à-vis the intrinsic value for ELC-shorts

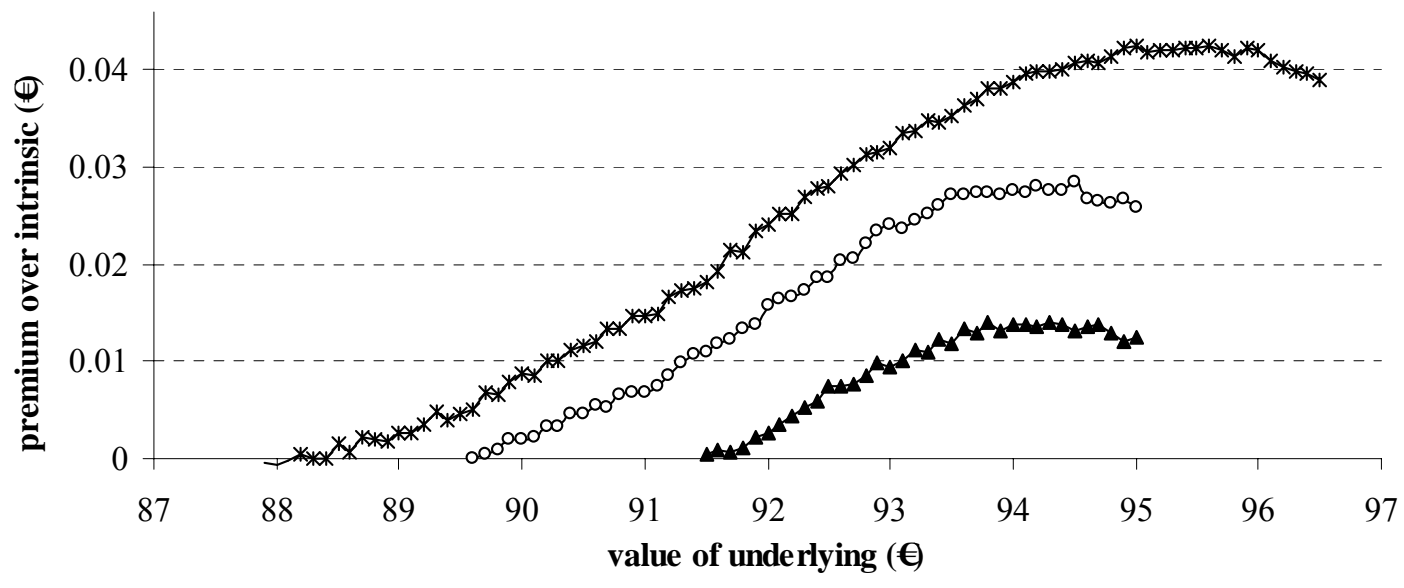

$\multimap \mathrm{K}=€ 95.24$; c.s. $=200 \mathrm{BP} \multimap \mathrm{K}=€ 95.24$; c.s. $=150 \mathrm{BP} \rightarrow \mathrm{K}=€ 96.62$; c.s. $=200 \mathrm{BP}$ 
Figure 4: Theoretical premiums versus observed premiums.

We compile 25,645 snapshots of ELC prices combined with financing levels and underlying prices. We multiply the ELC- and underlying prices by 100/D and plot the differences between rescaled prices and intrinsic values as a function of the rescaled price of the underlying. Panel A gives the picture for ELC-longs, Panel B for ELC-shorts. Notice that in both panels there are many observations that fall outside the graph. The bold lines are the Monte Carlo approximated theoretical prices for an ELC with $K=€ 103.5$ ( $€ 96.6$ for panel B) and a credit spread of 200 basispoints, written on a hypothetical typical DAX-stock.

\section{Panel A: ELC longs}

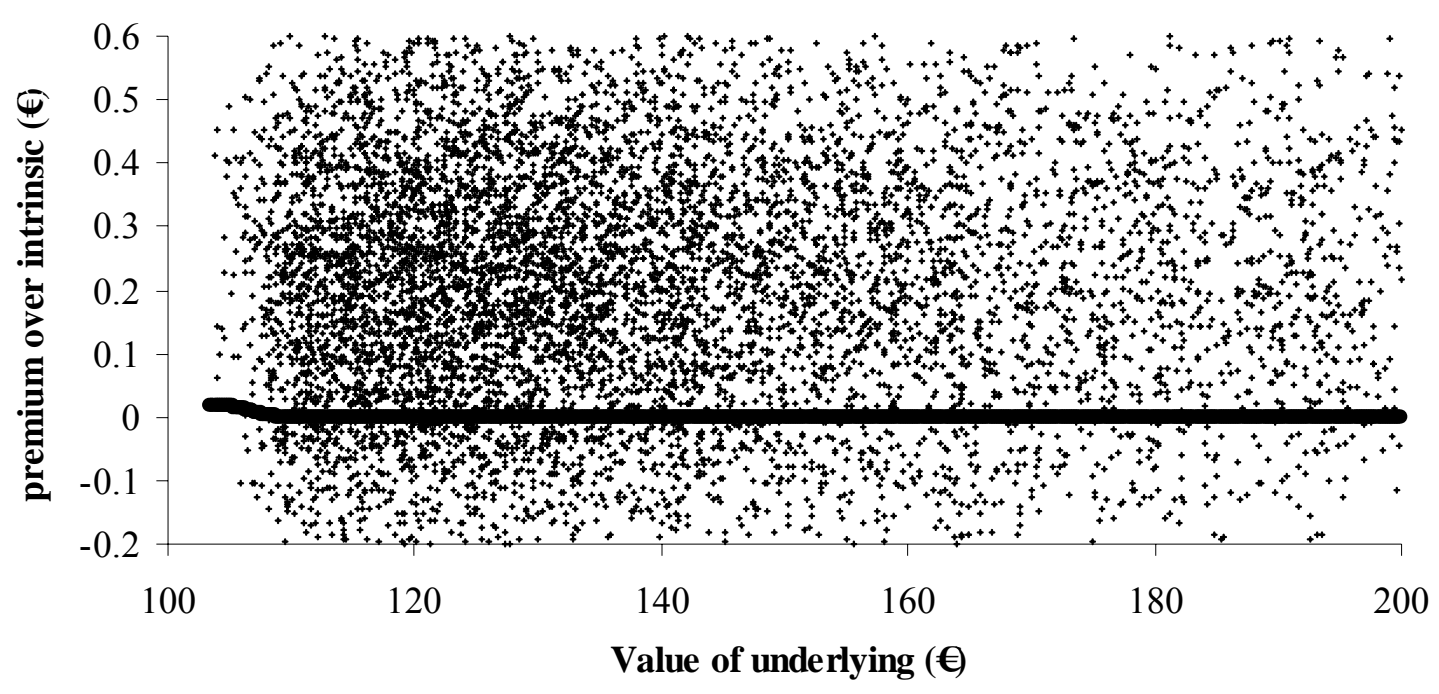

Panel B: ELC longs

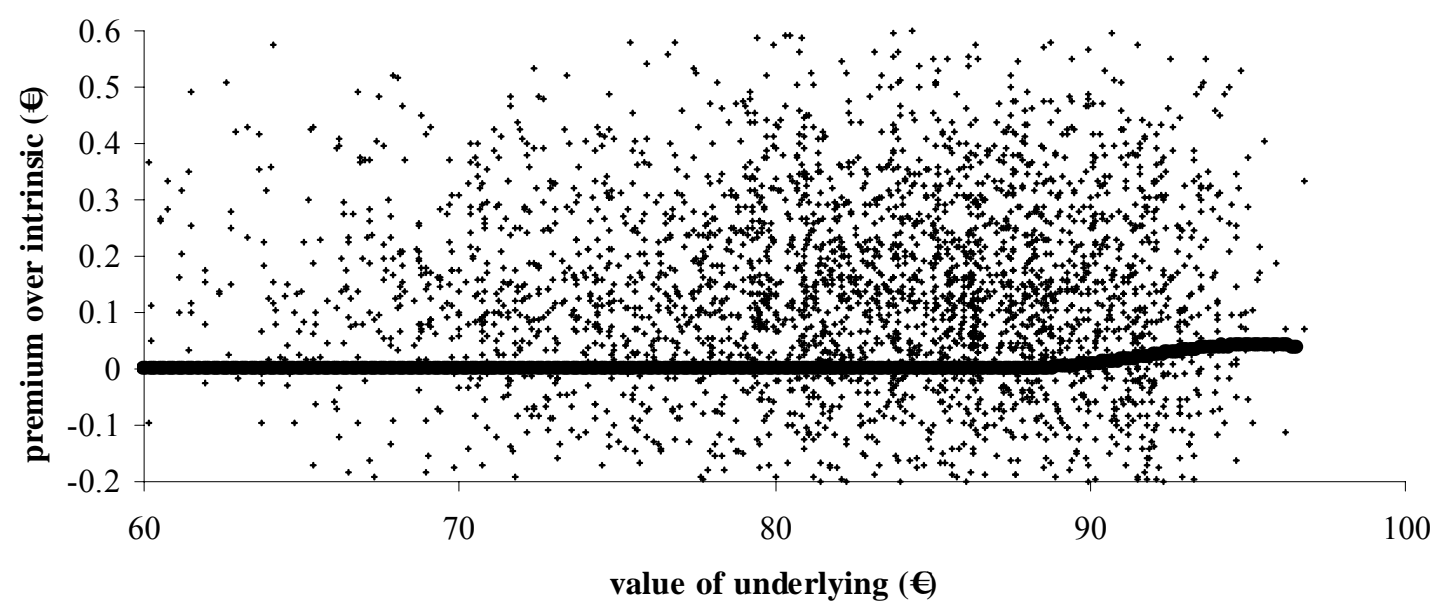




\section{Table 7: Residual Value Analysis}

We collect 1,801 residual values from the websites of four ELC-issuers who report alongside the residual value, stoploss level $K$ and financing level $D$. We compute the differences between the reported residual value and the theoretical stoploss value $|K-D|$ (times the ratio, if applicable). In panel A we describe the distribution of these residual value shortfalls for the entire sample and several subsamples. The "percentage zero" rows give the proportions of residual values that fell within a one $€$-cent rounding rage of the theoretical stoploss value.

\begin{tabular}{|c|c|c|c|c|c|c|c|c|c|}
\hline & \multicolumn{3}{|c|}{ Entire Sample } & \multicolumn{3}{|c|}{823 Longs } & \multicolumn{3}{|c|}{978 Shorts } \\
\hline & $\begin{array}{c}\text { absolute } \\
\text { shortfall } \\
€\end{array}$ & $\begin{array}{c}\text { relative } \\
\text { to }|K-D| \\
\%\end{array}$ & $\begin{array}{c}\text { relative } \\
\text { to } K \\
\% \\
\end{array}$ & $\begin{array}{c}\text { absolute } \\
\text { shortfall } \\
€\end{array}$ & $\begin{array}{c}\text { relative } \\
\text { to }|K-D| \\
\%\end{array}$ & $\begin{array}{c}\text { relative } \\
\text { to } K \\
\% \\
\end{array}$ & $\begin{array}{c}\text { absolute } \\
\text { shortfall } \\
€ \\
\end{array}$ & $\begin{array}{c}\text { relative } \\
\text { to }|K-D| \\
\% \\
\end{array}$ & $\begin{array}{c}\text { relative } \\
\text { to } K \\
\% \\
\end{array}$ \\
\hline average & -0.024 & -3.186 & -0.237 & -0.022 & -2.673 & -0.247 & -0.024 & -3.518 & -0.231 \\
\hline minimum & -1.86 & -100.00 & -11.04 & -1.86 & -77.01 & -9.95 & -0.68 & -100.00 & -11.04 \\
\hline median & 0.00 & -0.52 & -0.04 & 0.00 & -0.33 & -0.03 & 0.00 & -0.64 & -0.04 \\
\hline maximum & 0.36 & 48.37 & 3.74 & 0.36 & 33.33 & 3.74 & 0.36 & 48.37 & 2.55 \\
\hline standard deviation & 0.10 & 10.22 & 0.78 & 0.13 & 8.21 & 0.83 & 0.08 & 11.33 & 0.75 \\
\hline$\%$-age zero & 50.47 & & & 51.03 & & & 50.00 & & \\
\hline \%-age positive & 8.66 & & & 9.84 & & & 7.67 & & \\
\hline
\end{tabular}

\begin{tabular}{|c|c|c|c|c|c|c|}
\hline & \multicolumn{3}{|c|}{143 overnight triggers } & \multicolumn{3}{|c|}{1,658 daytime triggers } \\
\hline & $\begin{array}{l}\text { absolute } \\
\text { shortfall }\end{array}$ & $\begin{array}{l}\text { relative } \\
\text { to }|K-D|\end{array}$ & $\begin{array}{c}\text { relative } \\
\text { to } K\end{array}$ & $\begin{array}{l}\text { absolute } \\
\text { shortfall }\end{array}$ & $\begin{array}{l}\text { relative } \\
\text { to }|K-D|\end{array}$ & $\begin{array}{c}\text { relative } \\
\text { to } K\end{array}$ \\
\hline & $€$ & $\%$ & $\%$ & $€$ & $\%$ & $\%$ \\
\hline average & -0.027 & -8.56 & -0.54 & -0.024 & -2.722 & -0.211 \\
\hline minimum & -1.86 & -100.00 & -9.95 & -0.82 & -35.15 & -4.73 \\
\hline median & 0.00 & -0.73 & -0.04 & 0.00 & -0.20 & -0.02 \\
\hline maximum & 0.36 & 9.16 & 0.22 & 0.36 & 33.33 & 3.74 \\
\hline standard deviation & 0.13 & 9.42 & 1.06 & 0.10 & 10.29 & 0.76 \\
\hline$\%$-age zero & 10.49 & & & 53.92 & & \\
\hline$\%$-age positive & 0.70 & & & 9.35 & & \\
\hline
\end{tabular}

\begin{tabular}{|c|c|c|c|c|}
\hline & \multicolumn{4}{|c|}{ residual value shortfall relative to $K(\%)$} \\
\hline & Bank 1 & Bank 2 & Bank 3 & Bank 4 \\
\hline average & -0.237 & -0.238 & -0.445 & -0.109 \\
\hline minimum & -9.95 & -5.51 & -11.04 & -5.28 \\
\hline median & -0.03 & -0.08 & -0.03 & 0.00 \\
\hline maximum & 3.74 & 2.30 & 2.55 & 0.22 \\
\hline standard deviation & 0.74 & 0.56 & 1.89 & 0.77 \\
\hline percentage zero & 48.98 & 41.23 & 37.63 & 93.53 \\
\hline percentage positive & 13.38 & 3.46 & 16.13 & 2.88 \\
\hline observations & 894 & 386 & 93 & 285 \\
\hline
\end{tabular}




\section{Figure 5: Intraday Event Study}

We collect 226 stoploss triggers during August-October 2006 for ELC written on 42 German stocks for which we obtained intraday data from the Institut für Finanzwirtschaft, Banken und Versicherungen (FBV) of Karlsruhe University. For every second in the six hour window around the trigger event, we record the last traded price and the trading volume during the second. We plot the average rescaled stockprices, $P_{t}$ and the average trading volume relative to the day's average per second volume, $V_{t}$ for ELC-long and ELC-short triggers.

$P_{t}$ and $V_{t}$ are computed using: $P_{t}=100 \sum_{i=1}^{N} \frac{p_{i, t}}{K_{i}}$ and $V_{t}=\sum_{i=1}^{N} \frac{27,000 \cdot v_{t, i} p_{t, i}}{\sum_{t=09: 30: 01}^{17: 00: 00} v_{t, i} p_{t, i}}$

Panel A: Event study on 82 ELC-long triggers, plotted over a six hour event window

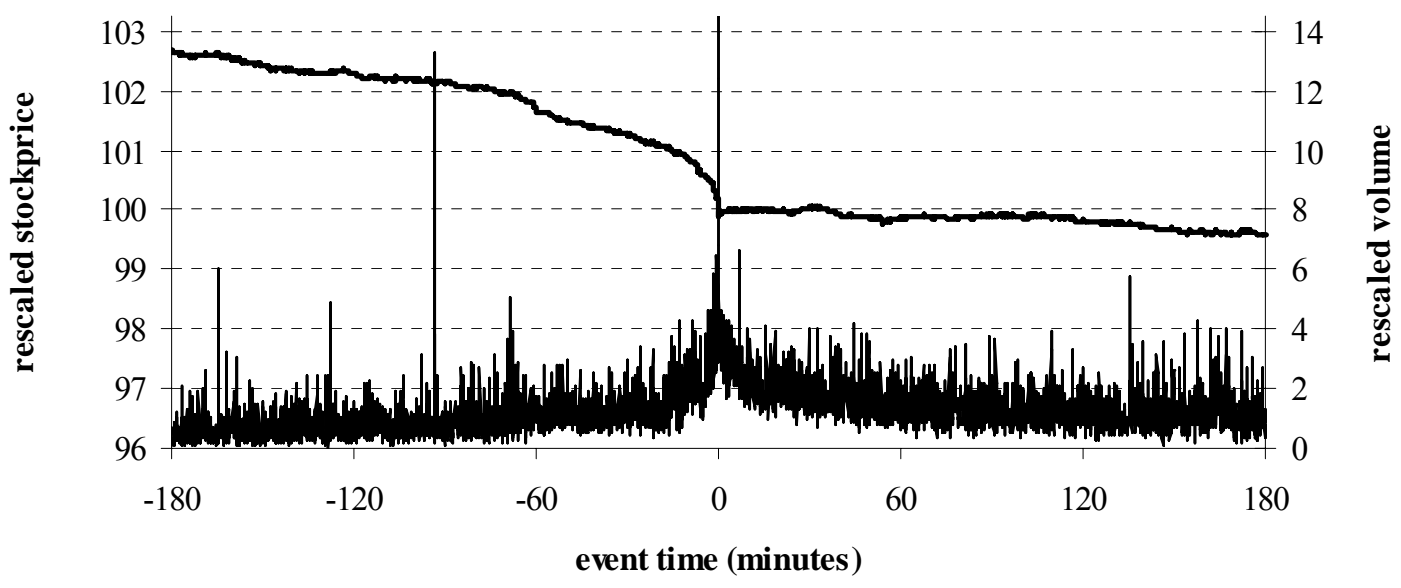

Panel B: Event study on 144 ELC-short triggers, plotted over a six hour event window

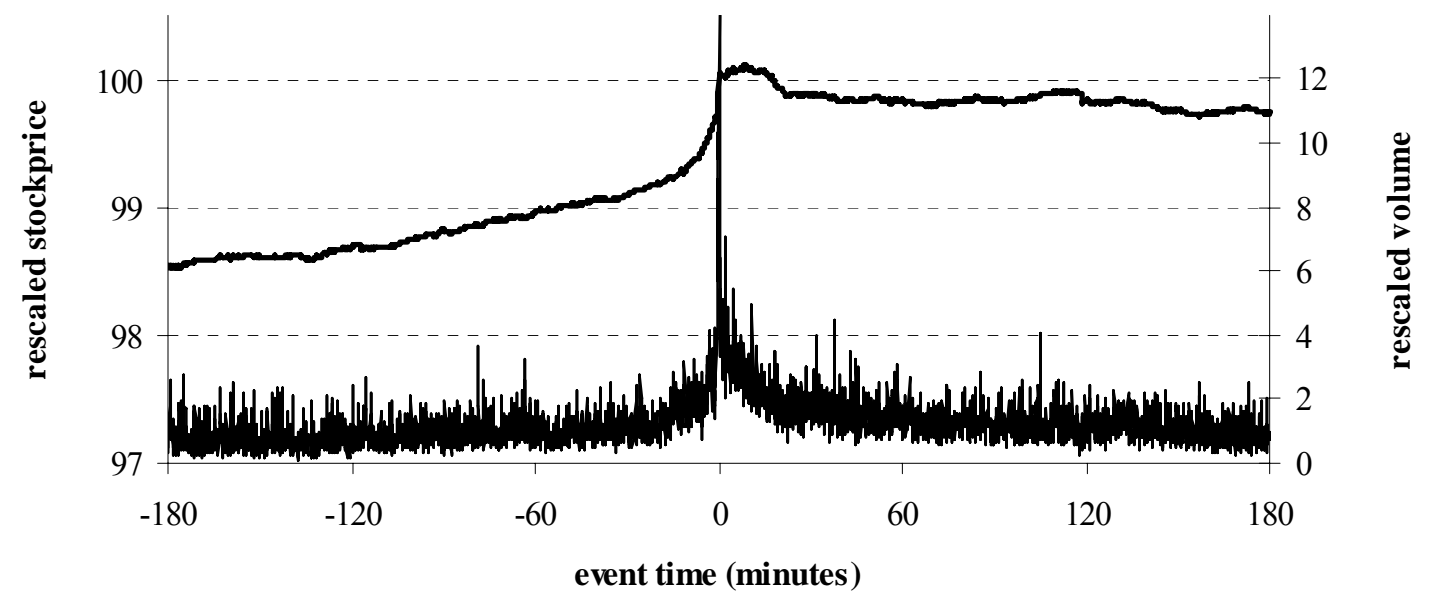


Figure 5: Intraday Event Study (continued)

Stockprice and volume plots plotted over a two minute event window around the stoploss trigger.

Panel C: Event study on 82 ELC-long triggers, plotted over a two minute event window

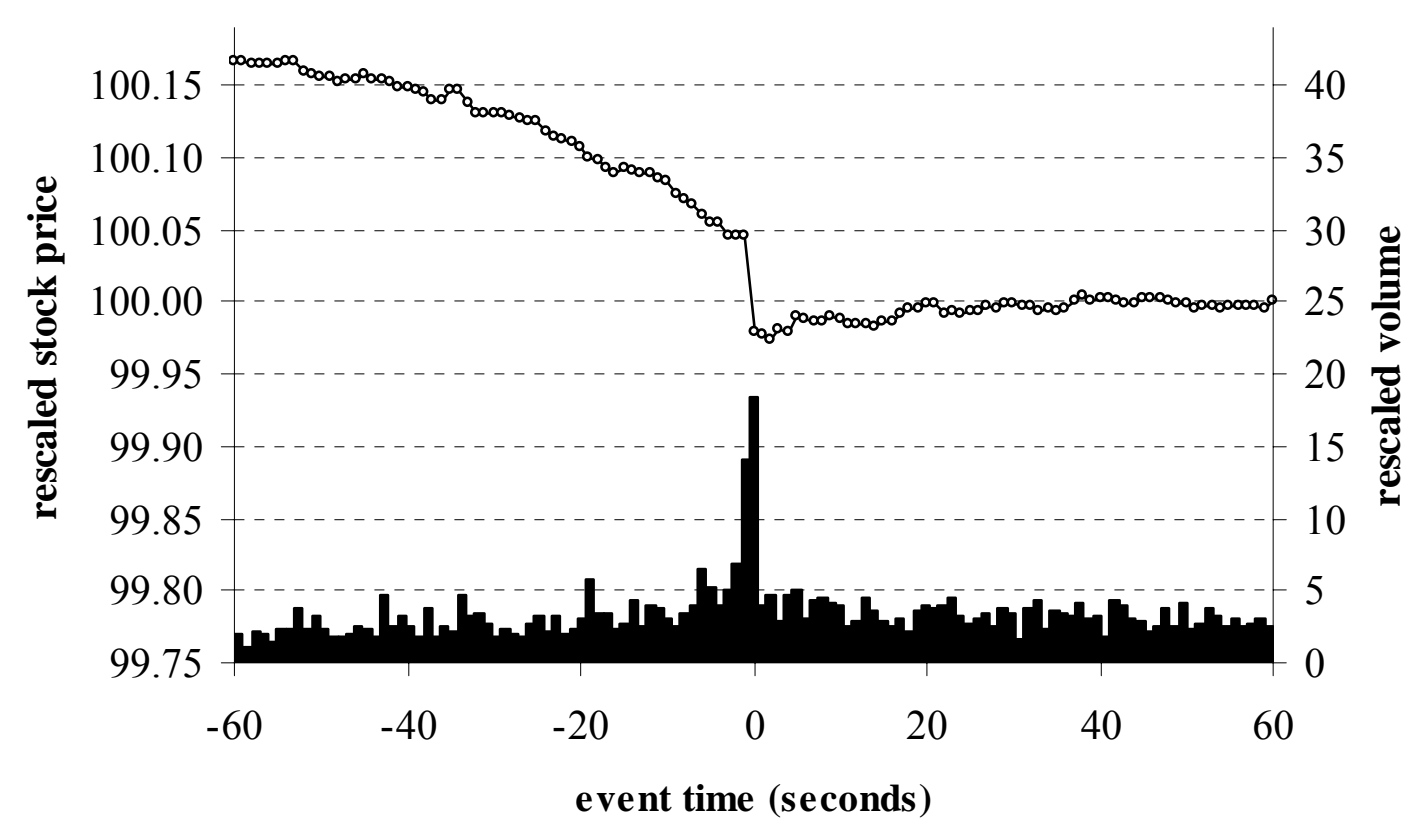

Panel C: Event study on 144 ELC-long triggers, plotted over a two minute event window

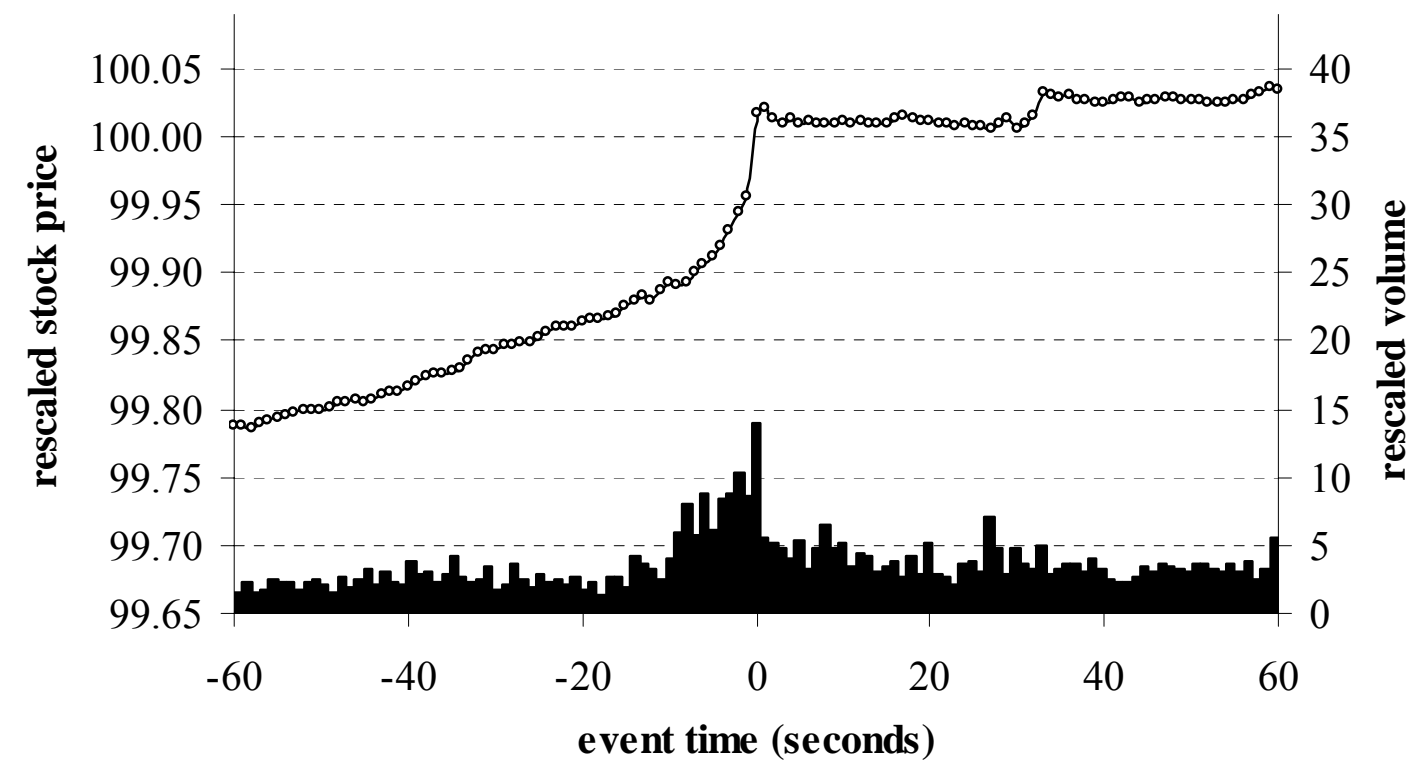

